\title{
A statistical DEM approach for modelling heterogeneous brittle materials
}

\author{
Albin Wessling $^{1}$ (I) $\cdot$ Simon Larsson ${ }^{1} \cdot$ Pär Jonsén $^{1} \cdot$ Jörgen Kajberg $^{1}$
}

Received: 28 May 2021 / Revised: 17 August 2021 / Accepted: 19 August 2021 / Published online: 3 September 2021

(c) The Author(s) 2021

\begin{abstract}
By utilizing numerical models and simulation, insights about the fracture process of brittle heterogeneous materials can be gained without the need for expensive, difficult, or even impossible, experiments. Brittle and heterogeneous materials like rocks usually exhibit a large spread of experimental data and there is a need for a stochastic model that can mimic this behaviour. In this work, a new numerical approach, based on the Bonded Discrete Element Method, for modelling of heterogeneous brittle materials is proposed and evaluated. The material properties are introduced into the model via two main inputs. Firstly, the grains are constructed as ellipsoidal subsets of spherical discrete elements. The sizes and shapes of these ellipsoidal subsets are randomized, which introduces a grain shape heterogeneity Secondly, the micromechanical parameters of the constituent particles of the grains are given by the Weibull distribution. The model was applied to the Brazilian Disc Test, where the crack initiation, propagation, coalescence and branching could be investigated for different sets of grain cement strengths and sample heterogeneities. The crack initiation and propagation was found to be highly dependent on the level of heterogeneity and cement strength. Specifically, the amount of cracks initiating from the loading contact was found to be more prevalent for cases with higher cement strength and lower heterogeneity, while a more severe zigzag shaped crack pattern was found for the cases with lower cement strength and higher heterogeneity. Generally, the proposed model was found to be able to capture typical phenomena associated with brittle heterogeneous materials, e.g. the unpredictability of the strength in tension and crack properties.
\end{abstract}

Keywords Bonded DEM $\cdot$ Heterogeneous brittle materials $\cdot$ Fracture $\cdot$ Brazilian disc $\cdot$ Weibull

\section{Introduction}

The fracture process of brittle heterogeneous materials is of vital importance for several industries. While the mechanical response of these materials is dependent on the mechanical properties of its constituent minerals or materials, discontinuities within the material significantly affects the response as well. For example, on a micromechanical scale these discontinuities may consist of microcracks, pores and grain boundaries cementing the different minerals together. Further, the grains can exhibit geometrical heterogeneities due to grain size, shape and orientation, but also mechanical heterogeneity due to varying strengths and elastic properties. Apart from the effect on the mechanical response, the

Albin Wessling

albin.wessling@1tu.se

1 Division of Mechanics of Solid Materials, Luleå University of Technology, 97187 Luleå, Sweden micromechanical discontinuities also influences the initiation, propagation and coalescence of cracks, which are well known to be key aspects of the fracture process. By utilizing numerical models and simulation, these phenomena can be studied in a controlled environment and give valuable insight into aspects of the fracture process that would otherwise be expensive, difficult or even impossible to obtain experimentally. These insights based on numerical simulations can increase the knowledge and understanding of processes involving the fracture of brittle heterogeneous materials, which in turn can aid for optimizing e.g. rock drilling in geothermal applications or the comminution process in mining industries.

Within the framework of the traditional Finite Element Method (FEM), several recent publications with emphasis on modelling of heterogeneous brittle materials can be found. Saadati et. al. investigated the fracture of granite by combining a plasticity model of compression and a damage model for tension [42]. Here, the closure of pores due to compres- 
sion was represented by an irreversible volumetric strain, affecting the bulk modulus of the material and making the material more compact. Further, by employing a weakest link approach based on the Weibull distribution [51], defects with different orientations and dimensions were distributed within the model, and a cohesive model was employed to capture the residual strength at the crack. Using the edgeon impact test, the authors found that the model was in agreement with experimental results with regards to crack density and fracture pattern. This model approach has later been applied to investigate the effects of preexisting cracks on tensile strength of granite subjected to high strain rates [41] and the contact-induced damage from cyclic and monotonic indentation of granite [34]. A micromechanical fracture model of a heterogeneous ceramic composite was developed by Zhai and Zhou [56]. Here, the arbitrary microstructure was explicitly accounted for and the authors were able to analyse the crack propagation and branching. Saksala et. al. investigated the applicability of polygonal finite elements for $2 \mathrm{D}$ for rock mechanics where the mesostructure of the rock was represented by assigning material properties of constituent minerals to different elements [43]. Although lacking of predictability, the authors concluded that the model is suitable for rock mechanics. A statistical approach for modelling heterogeneous concrete, where the different phases were represented by a statistical distribution of constituent phases, has previously been developed within the framework of FEM [36]. For heterogeneous material a combined FEM and a nonlinear cohesive model to simulate compacted metal powder was presented and validated in [21]. Furthermore, a developed version of the model including a nonlinear elastic model was reported in [22].

Even though some insight can be gained by using a continuum method, this approach is inherently limited for describing the fracture process of a discontinuous material, such as rock [38]. In contrast to the continuum methods, the damage onset of direct methods are modelled directly by tracking the formation and propagation of each microcrack. One such direct method is the Discrete Element Method (DEM), originally formulated by Cundall and Strack $[7,8]$ for modelling of granular assemblies. Here, the assembly is represented by a set of rigid spheres that interact through contact laws at their contact interface. This method has found a widespread application for simulations of industrial processes involving granular media, such as for wet stirred mills $[26,27]$, tumbling mills $[20,23]$, and other large-scale industrial processes [5]. An extension to the conventional DEM is the Bonded-Particle Model (BPM) [38], where, in parallel with the DEM contact, a set of linear elastic springs, or parallel-bonds, are distributed between the particles. These bonds can transmit force and moment between two contacting particles and if the corresponding stress exceeds the pre-described strength, the bond breaks. Spontaneous crack initiation occurs on a micromechanical scale with a broken bond, propagates through the media through more broken bonds and coalesce with other cracks to form larger fracture planes. In this way, the BPM is able to naturally describe the initiation, propagation and coalescence of cracks within brittle heterogeneous materials.

Ever since its formulation, the BPM has been a widely popular tool for investigating problems involving brittle fracture. Examples where the BPM has been applied to industrial processes can be found for rock indentation [15,58], drilling of soil [48] and rock [45] and rock cutting [16,39]. The BPM has also been proven to be a suitable framework for virtually reproduce the fracture process of brittle materials for common experimental methods, such as the uniaxial compression test of concrete [49] and granite [55] as well as the Brazilian disc test of transversely isotropic rock [53]. The calibration process is often conducted by trial-and-error; however, more intelligent methods have been utilized, e.g. using a local constitutive model [33], employing a dimensional analysis of the micromechanical parameters [40] or using calibration schemes based on uniaxial and triaxial tests [50]. Some simulations based on the BPM have been found to exhibit unrealistically low compression to tension ratios, making it impossible to match both the compressive and tensile strength for some cases. As the authors stated in the original formulation of the BPM [38], this mismatch is probably due to the use of spherical grains and could be reduced by utilizing more complex-shaped and highly interlocked grains. This has been explored by other authors, such as increasing the interlocking of particles by increasing the interaction range [44] and utilizing clumped particles to represent irregular grains [4]. It has also been shown that employing a displacement-softening contact law [31] reduces this issue. Another solution to this issue is the Grain-Based Model (GBM) [37], where the irregular grains are represented by polygonal elements, filled with parallel-bonds, that are connected to each other through smooth-joint interfaces [18]. This approach has been used to evaluate phenomena connected to damage evolution and microcracking of granite [14] and the effect of pre-existing cracks [57] and grain size heterogeneity effect [35] of crystalline rocks.

In the original formulation of the BPM, the heterogeneity of the rock material is introduced by the particle size distribution. Other approaches for introducing heterogeneity with the BPM is the use of irregular grain shapes and statistical distributions of the micromechanical parameters of the BPM, both of which have been used before in the literature, see e.g. the grain-based approaches in [14,29]. However, no study can be found regarding the repeatability of results, such as crack properties and macromechanical strength, when using these approaches. To this end, the present study uses the BPM to evaluate the effects that variations of grain properties have on the macroscopic repeatability. A new approach for rep- 


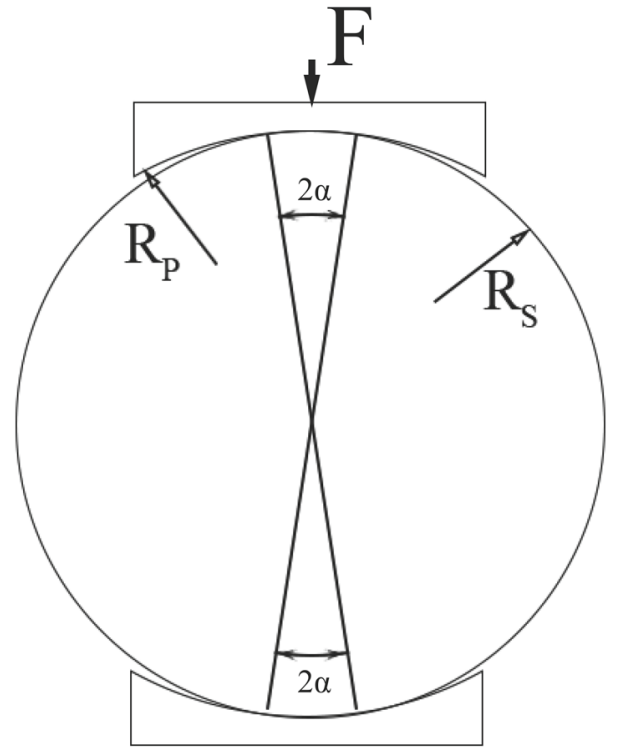

Fig. 1 A schematic view of the Brazilian disc test

resenting the heterogeneous brittle materials is presented, where the grains are randomly assigned to the rock model as irregular ellipsoids throughout the body. Compared to the aforementioned grain-based methods, the current model does not consider specific constituent minerals. Instead, a more holistic approach is used, where each grain obtains its mean micromechanical parameters from the Weibull distribution. The model is applied to the Brazilian disc test, where the initiation, propagation and coalescence of cracks as well as macroscopic tensile strength are evaluated for different heterogeneities and intergranular cementing strengths.

\section{Materials and methods}

This section covers the methodology used in this study. This includes a description of the Brazilian Disc Test (BDT) and fundamental theory about the Discrete Element Method (DEM) and Bonded-Particle Method (BPM). The proposed model is also described in this section, i.e. the grain generation process and grain cementing. Lastly, the numerical cases investigated in this study are described.

\subsection{Brazilian disc test}

The diametral compression test, or Brazilian Disc Test (BDT), is an experimental method for measuring the indirect tensile strength of brittle materials, such as concretes [3] and rocks [6,28], but also for compact powders [21]. In this test, a circular disc is compressed diametrically over a finite arc of length $2 \alpha$, see Fig. 1, which induces tensile stresses to a zone close to the vertical centre line of the specimen. For a distributed compressive load $F$, applied to a disc of diameter $D$ and thickness $t$, Hondros showed that the induced tensile stress at the centre of the disc is given by $[2,13]$

$\sigma_{t}=\frac{2 F}{\pi D t}$

It is important to note that the indirect tensile strength obtained from Eq. (1) is only an estimation of the tensile strength as obtained from direct testing methods. Further, the splitting crack has to initiate at the centre of the disc in order for the test to be accurate. This is seldom the case, however, as the initiation point is known to deviate from the centre [10] and even initiating from the loading plates [46]. Cracks initiating from loading plates are more prevalent for versions of the test that uses flat loading plates, such as the version suggested by ASTM [1], due to the stress concentration associated with the point load. The curved loading jaws reduces the stress concentrations at the loading point [32] and is the ISRM recommended method. The suggested jaw radius is 1.5 times the radius of the sample, i.e. $R_{P}=1.5 R_{S}$, which results in a contact arc of approximately $2 \alpha=10^{\circ}$, see Fig. 1.

Even though the BDT has inherent challenges, it is still the preferred method for measuring the tensile strength of heterogeneous brittle materials due to its simplicity compared to direct methods. The crack initiation and propagation of the BDT, as well as the validity and applicability of the method, is still researched today [28]. In the present work, the quasi-static BDT was simulated in order to evaluate the capabilities of the suggested numerical model. Further, in order to increase the knowledge about the test itself, the crack initiation, propagation and coalescence of cracks as well as the predicted tensile strength were evaluated.

\subsection{Discrete element method}

In the Discrete Element Method (DEM), the granular material is modelled using a set of rigid discrete spheres $[7,8]$. A key feature about the DEM is the individual treatment of each element - the motion of each sphere is resolved through the integration of Newton's second law,

$m_{i} \frac{\mathrm{d} \boldsymbol{v}_{i}}{\mathrm{~d} t}=\boldsymbol{F}_{i}$

where $m_{i}$ and $\boldsymbol{v}_{i}$ are the mass and velocity of particle $i$, respectively. The total force acting on particle $i$ may be expressed as

$$
\boldsymbol{F}_{i}=\boldsymbol{F}_{i}^{\text {ext }}+\sum_{j=1}^{n_{j}} \boldsymbol{F}_{i j}
$$


where $\boldsymbol{F}_{i}^{\text {ext }}$ are the external forces, such as gravity, $n_{j}$ is the number of neighbouring particles and $\boldsymbol{F}_{i j}$ are the contact forces between particles $i$ and $j$. The angular motion is governed by

$\boldsymbol{I}_{i} \frac{\mathrm{d} \boldsymbol{\omega}_{i}}{\mathrm{~d} t}=\sum_{j} \boldsymbol{M}_{i j}$

where $\boldsymbol{I}_{i}$ and $\boldsymbol{\omega}_{i}$ is the moment of inertia and angular velocity of particle $i$, respectively, and $\boldsymbol{M}_{i j}$ is the applied torque from particle $j$.

In the present study, the contact forces between particles are represented by a linear spring-dashpot model for both the normal and tangential direction $[24,30]$. In total, there are five governing parameters for particle-particle interaction, namely normal and shear spring constants, $k_{n}$ and $k_{s}$, normal and tangential damping coefficients, $c_{n}$ and $c_{t}$, as well as the sliding friction $\mu$. In order to obtain the velocities from Eqs. (2) and (4), an explicit time integration scheme was used in the present study.

In order to model a solid body of rock material, the DEM was extended to the BPM by Potyondy and Cundall [38]. Here, the rock is described as an assembly of cemented particles. This cementing, or bonding, of the particles work in parallel with the standard DEM formulation. These bonds can break and the failure criteria are expressed as

$$
\begin{aligned}
& \bar{\sigma}^{\max }=\frac{-\bar{F}^{\mathrm{n}}}{A}+\frac{\left|\bar{M}^{\mathrm{s}}\right| \bar{R}}{I} \geq \sigma_{c} \\
& \bar{\tau}^{\max }=\frac{\left|\bar{F}^{\mathrm{s}}\right|}{A}+\frac{\left|\bar{M}^{\mathrm{n}}\right| \bar{R}}{J} \geq \tau_{c}
\end{aligned}
$$

where $A$ is the bond area and $\mathrm{I}$ and $\mathrm{J}$ are the moment and polar moment of inertia of the bond. The radius of the bond between two particles $A$ and $B$ is given as the minimum of the bonding particles radii, i.e. $\bar{R}=\bar{\lambda} \min \left(R^{A}, R^{B}\right)$. In this study, a homogeneous particle radius was used and the radius multiplier $\bar{\lambda}$ was set to unity. The tensile and shear bond strengths are represented by $\sigma_{c}$ and $\tau_{c}$, respectively, and the bond breaks permanently and instantaneously once either the tensile stress or shear stress exceeds its limit value. The bond forces $\left(\bar{F}^{n}\right.$ and $\left.\bar{F}^{s}\right)$ and moments $\left(\bar{M}^{n}\right.$ and $\left.\bar{M}^{s}\right)$ are calculated incrementally each time step according to

$$
\left\{\begin{array}{l}
\Delta \bar{F}^{n}=\bar{k}^{n} A \Delta U^{n} \\
\Delta \bar{F}^{s}=-\bar{k}^{s} A \Delta U^{s} \\
\Delta \bar{M}^{\mathrm{n}}=-\bar{k}^{s} J \Delta \theta^{n} \\
\Delta \bar{M}^{s}=-\bar{k}^{n} I \Delta \theta^{s}
\end{array}\right.
$$

where $\bar{k}^{n}$ and $\bar{k}^{s}$ is the normal and shear bond stiffness, respectively. The relative displacement and rotation in Eq. (7)

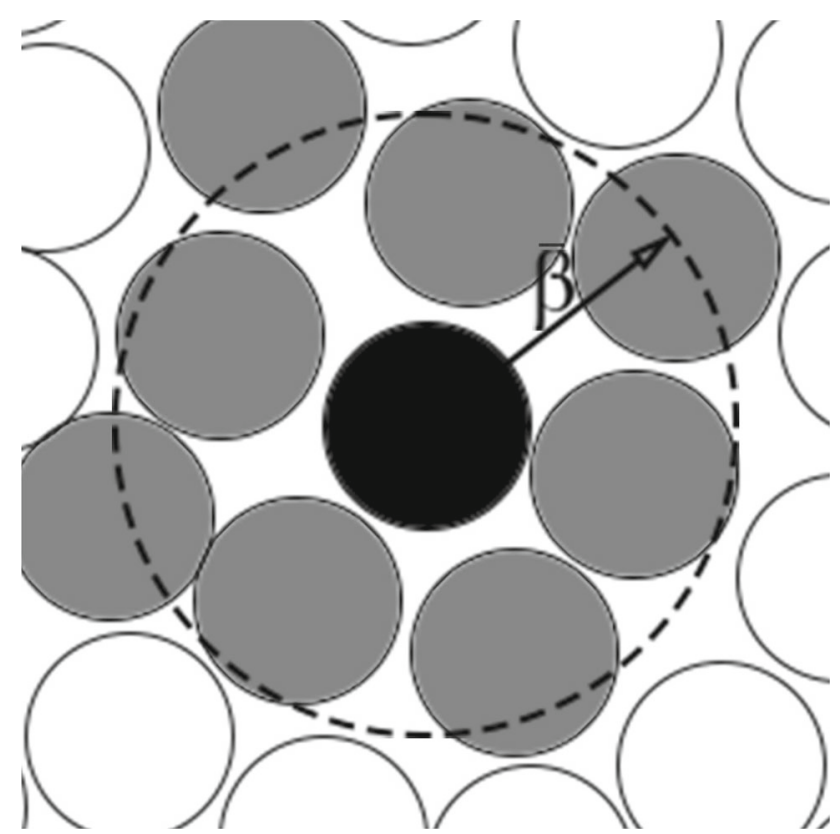

Fig. 2 A two-dimensional representation of the interaction range $\bar{\beta}$

are represented by $\Delta U^{n / s}$ and $\Delta \theta^{n / s}$. In Eqs. (5-7) the upper index $n$ and $s$ denotes the normal and shear direction, respectively. The BPM also utilize a local non-viscous damping $\bar{\alpha}$ in order to account for the energy dissipation from e.g. internal friction. The damping force applied to each particle is given by [38]

$\boldsymbol{F}_{i}^{d}=-\alpha\left|\boldsymbol{F}_{i}\right| \operatorname{sign}\left(\boldsymbol{v}_{i}\right)$

Lastly, the amount of particle interlocking is controlled via the interlocking range $\bar{\beta}$. In other words, $\bar{\beta}$ is the perimeter to perimeter distance that allow for bonding between two discrete element spheres, see Fig. 2.

To conclude, apart from the particle radius, the BPM has a total of 11 input parameters, whereof five of them are related to the original DEM formulation, $k_{n}, k_{s}, c_{n}, c_{s}$ and $\mu$, and five of them are related to the bonds between the particles, $\bar{k}_{n}, \bar{k}_{s}, \bar{\sigma}_{c}, \bar{\tau}_{c}, \bar{\beta}$ and $\bar{\alpha}$. The parameter values used in this study are presented and motivated in Sect. 2.5.

\subsection{Grain generation process}

In the proposed numerical model for brittle heterogeneous materials, the heterogeneity properties was introduced into the BPM in two ways. Firstly, the grains are constructed as ellipsoidal subsets of spherical discrete elements. The sizes and shapes of these ellipsoidal subsets are randomized, which introduces a grain shape heterogeneity, see Fig. 3. Secondly, the intragranular structure was constructed using parallel bonds with mean micromechanical parameters chosen according to the Weibull distribution. Four 


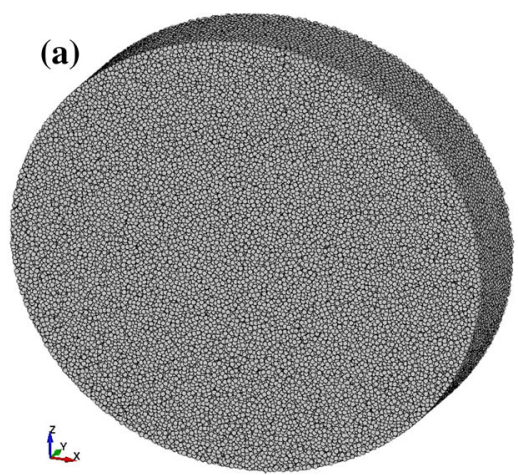

(d)

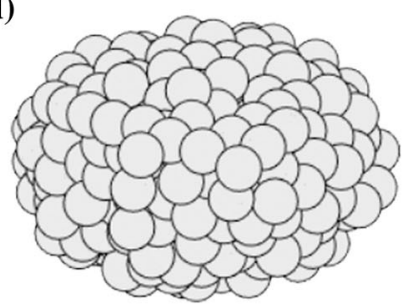

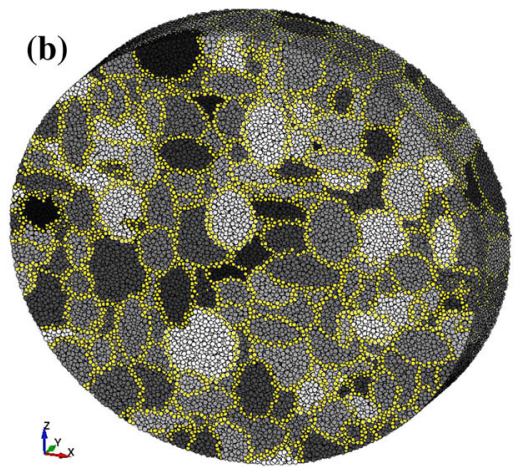

(e)

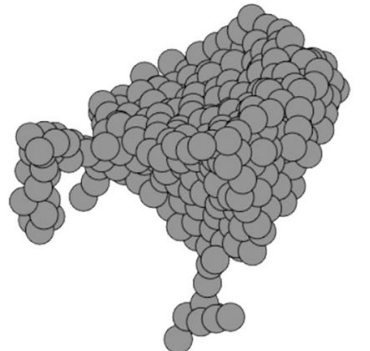

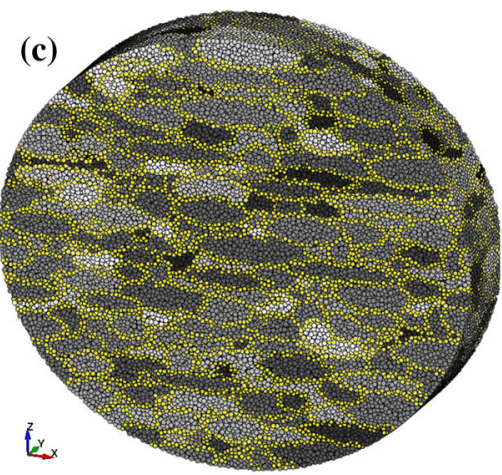

(f)

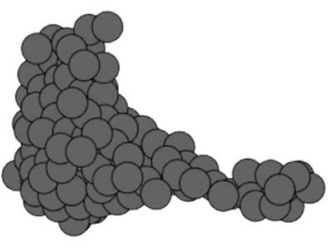

Fig. 3 The grain generation process of samples for the Brazilian disc test, where the grains are represented by ellipsoidal subsets of discrete element spheres. The different greyscale colouring represents the mean micromechanical strength of the grains, where a darker colour corresponds to weaker grains. The yellow particles corresponds to grain boundaries. Initial node distribution (a), an example of a sample with

micromechanical parameters were governed by the Weibull distribution: the normal and shear stiffness and the tensile and shear strengths. The probability density function for a micromechanical parameter $\eta$ is given by [51]

$f\left(\eta, \eta_{0}, m\right)=\frac{m}{\eta_{0}}\left(\frac{\eta}{\eta_{0}}\right)^{m-1} e^{-\left(\eta / \eta_{0}\right)^{m}}$

where $\eta_{0}$ is the scale parameter and $m$ is the shape parameter (or heterogeneity index). A larger variation is obtained for a smaller shape parameter, i.e. a smaller value of the shape parameter corresponds to a more heterogeneous distribution of the microparameter. For the case of a very large value of the shape parameter, above $10^{6}$, the distribution is practically constant. The cumulative Weibull distribution function for different shape parameters is shown in Fig. 4.

For a given sample geometry discretized with rigid spheres of uniform size, such as the one in Fig. 3a, the grains were distributed throughout the body by performing the following steps:

1. A parent discrete element sphere was randomly selected within the domain and the mean grain micromechanical properties were obtained from the Weibull distribution.

2. A randomized ellipsoid was created around the parent discrete element sphere by generating the radii uniformly, i.e. equal grain radii distributions for $x, y$ and $z(\mathbf{b})$, an example of an anisotropic sample with a preferred grain direction, i.e. the radii distribution of the $x$-direction is larger than for the other directions (c), example of a regular ellipsoidal subset of discrete spheres (d) and examples of irregular ellipsoidal subset of discrete spheres $(\mathbf{e}-\mathbf{f})$

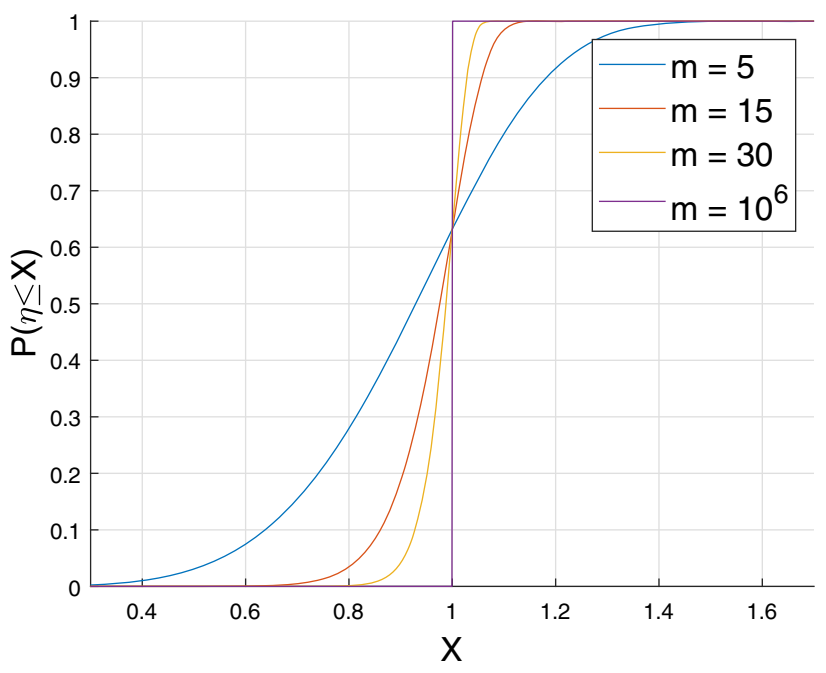

Fig. 4 The cumulative Weibull distribution for different shape parameters $m$

$R_{x}, R_{y}, R_{z} \sim U\left(R_{\min }, R_{\max }\right)$

where $U\left(R_{\min }, R_{\max }\right)$ is the uniform distribution between $R_{\min }$ and $R_{\max }$.

3. All particles within the ellipsoid were bound together within $\pm 10 \%$ of the mean grain values and then excluded from future grain bonding.

4. Steps (1)-(3) were repeated until no particles were left. 
An example of a generated sample for the Brazilian disc test can be seen in Fig. 3b. Here, a particle radius of $0.1 \mathrm{~mm}$ and $\left(R_{\min }, R_{\max }\right)_{x, y, z}=(0.9,2.9) \mathrm{mm}$ were used, resulting in a grain size distribution of $0.5-4 \mathrm{~mm}$. This sample configuration was used for the main part of the study. A few samples with anisotropic grains were also evaluated. These samples were created by allowing the grains to be slightly elongated within the $\mathrm{x}$ direction, $\left(R_{\min }, R_{\max }\right)_{x}=(0.9,5) \mathrm{mm}$, and slightly shorter along the $y$ and $z$ direction, $\left(R_{\min }, R_{\max }\right)_{y, z}$ $=(0.9,1.55) \mathrm{mm}$.

The first few grains generated were likely to be ellipsoidal, as seen in Fig. 3d. As more particles were excluded from bonding, more irregular grain shapes were obtained, such as the ones seen in Fig. 3e, f. It should be noted that, due to limitations of the software used in this study, no possibility for continuous Weibull distribution of the grain microparameters was possible. Instead, 1500 values of each parameter were considered sufficient and were distributed to the grains. Further, the normal and shear bond strengths were coupled, with the consequence that a lower normal strength is followed by a lower shear strength, and vice versa. For the generated samples in Fig. 3, and throughout this work, the greyscale colouring denotes the average strengths of the grains, with black denoting the weakest grains.

\subsubsection{Grain cementing model}

In order to obtain a statistical variation for the intergranular binding, a cementing model with properties based on the grains being bound was used. Given a rock body with distributed subsets of discrete spheres (or grains), the cementing process is as follows. First, one of the subsets in the rock body is selected at random. Let this random subset be denoted by $G_{i}$. The neighbouring subsets $G_{j}$ are then identified as the subsets that have discrete spheres within interaction range $\bar{\beta}$ of the discrete spheres of subset $G_{i}$. In other words, $G_{j}$ is a neighbour of $G_{i}$ if, for all sets of distances $d_{i j}$ between constituent discrete spheres of the two subsets, any $d_{i j} \leq \bar{\beta}$. The particles of $G_{j}$ within interlocking range of $G_{i}$ are then cemented together using parallel bonds with normal and shear strengths according to

$$
\left\{\begin{array}{l}
\bar{\sigma}_{c}^{i j}=C_{f} \cdot \bar{\sigma}_{c}^{i} \\
\bar{\tau}_{c}^{i j}=C_{f} \cdot \bar{\tau}_{c}^{i}
\end{array}\right.
$$

where $\bar{\sigma}_{c}^{i j}$ and $\bar{\tau}_{c}^{i j}$ are the normal and shear bond strength of the cement, $\bar{\sigma}_{c}^{i}$ and $\bar{\tau}_{c}^{i}$ are the mean normal and shear bond strengths of grain $G_{i}$ and $C_{f}$ is the cement scaling parameter. The process is repeated until all grain pairs have been identified and cemented together. Within this work, the grain boundaries are highlighted by yellow discrete spheres, e.g.

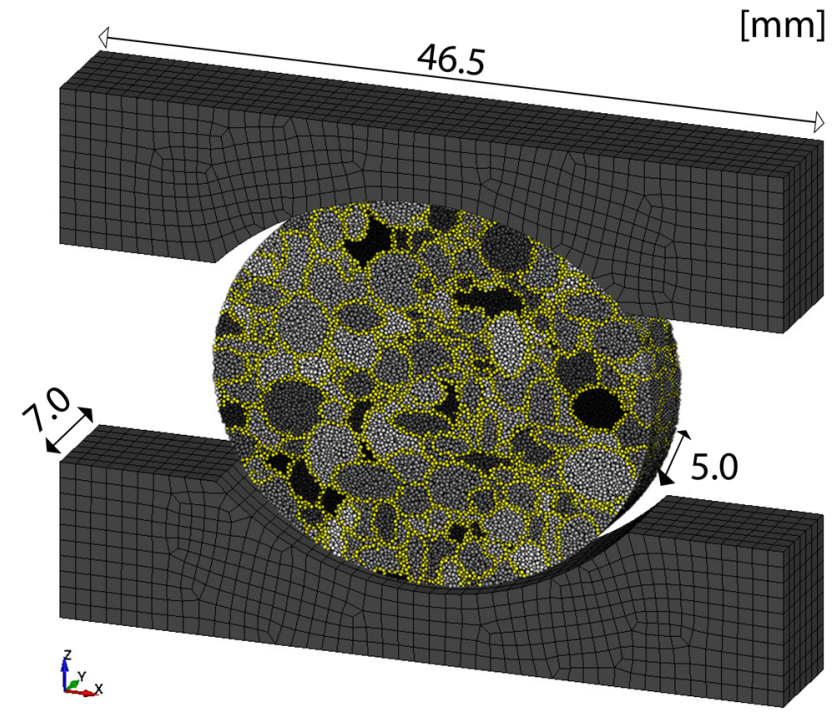

Fig. 5 The sample and loading jaw configuration used for the simulations of the Brazilian disc test. The samples have a diameter of $25 \mathrm{~mm}$ and a thickness of $5 \mathrm{~mm}$. The jaws have radius $18.75 \mathrm{~mm}$

as in Fig. 3; however, only half of the boundary nodes (the ones associated with the grain $G_{i}$, see above) are visible for clarity. It should be noted that, using this cementing procedure, some of the discrete spheres represents pure cement between two grains instead of the grain itself.

\subsection{Numerical setups}

For the numerical setup of the BDT, the standard procedures established by ISRM [2] were employed. However, the standard suggests a sample diameter of at least 10 times the largest grain size. The largest grain size of the samples generated within this study is roughly $4 \mathrm{~mm}$, which would require a sample diameter of at least $40 \mathrm{~mm}$. For the sake of computational efficiency, a sample diameter of $25 \mathrm{~mm}$ was used instead. The thickness of all the samples was $5 \mathrm{~mm}$, which is the smallest allowed thickness for a diameter of 25 $\mathrm{mm}$.

The radius of the loading jaws was set to 1.5 times the sample radius $(18.75 \mathrm{~mm})$, which should keep the contact arc between $5^{\circ}$ and $10^{\circ}$ (depending on the deformability of the jaws and sample) [28]. The numerical setup can be seen in Fig. 5. The compressive loading was applied via a prescribed velocity of the upper jaw. In order to select an appropriate loading jaw velocity, with regards to computational time and the explicit time integration scheme, the effects that the velocity had on the mechanical response and predicted strength was evaluated, see Fig. 6. As can be seen from this test, apart from the oscillations, there was almost no impact from loading jaw velocity due to the high amount of damping present in the model (see Sect. 2.5). A velocity of $0.3 \mathrm{~mm} / \mathrm{s}$ gave a stable 


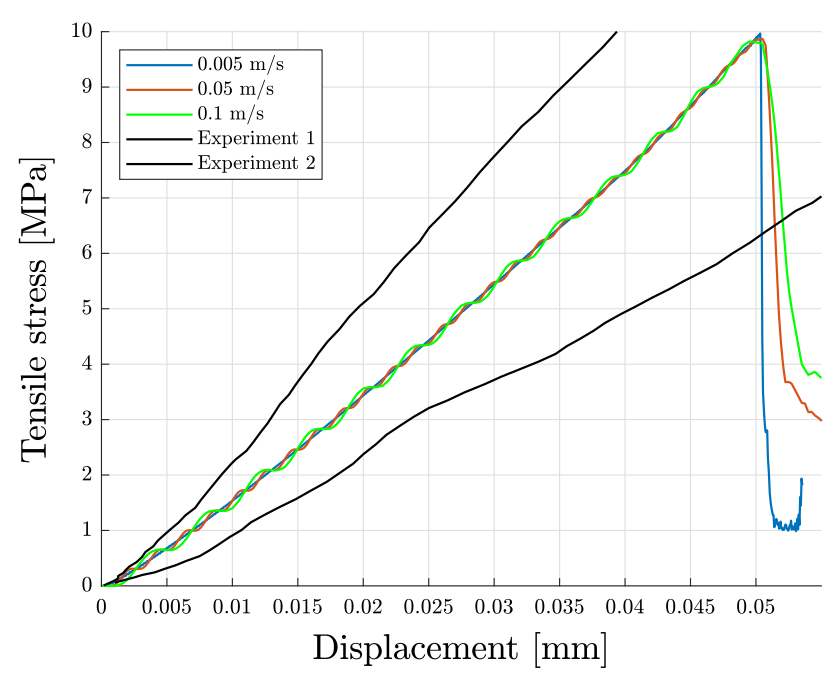

Fig. 6 The loading jaw velocity effect on the mechanical response of the numerical setup of the Brazilian disc test. The black curves are examples of Brazilian disc tests of granite [52]

loading and was used for all simulations. The BDT samples were discretized with particles of uniform radii $R=0.1 \mathrm{~mm}$, resulting in roughly 313,000 particles. For each loading jaw, a linear elastic FEM representation of approximately 3,000 solid hexagonal elements were used with elastic modulus 210 $\mathrm{GPa}$ and Poisson's ratio 0.3 .

In order to evaluate the proposed model, a large set of samples was generated and simulated. Two key parameters of the model were varied simultaneously - the cement scale factor $C_{f}$ and the Weibull shape parameter $m$-and 10 samples were simulated for each pair of parameters. Three cement scale factors, $C_{f}=0.25, C_{f}=0.50$ and $C_{f}=0.75$, were evaluated for three different shape parameters, $m=5, m=15$ and $m=30$. Further, 10 anisotropic samples, with $C_{f}=0.25$ and $m=15$, were generated and simulated twice (loaded once along the $z$-direction and once along the $x$-direction). In total, 100 samples were generated and 110 simulations were conducted. A summary of the different cases can be seen in Table 1. With regards to the BDT, the predicted tensile strength and crack properties were evaluated in detail. It should be noted that this study does not concern a specific material. Instead, the results focus on the versatility of the model and the complexity of the BDT.

\subsection{Calibration}

A challenge with the BPM is the extensive calibration procedure required to determine the set of microparameters that describes the macroscopic behaviour of the target material. This section describes the simplified calibration procedure used to determine the 11 parameters of the DEM and BPM, as described in Sect. 2.2. A common approach for determining the parameters is to simulate the BDT and Uniaxial
Table 1 The cement scaling factors of Eq. (13) and shape parameters of Eq. (9) used for the different cases

\begin{tabular}{llc}
\hline Case & Cement scale factor $C_{f}$ & Shape parameter $m$ \\
\hline 1 & 0.25 & 5 \\
2 & 0.25 & 15 \\
3 & 0.25 & 30 \\
4 & 0.50 & 5 \\
5 & 0.50 & 15 \\
6 & 0.50 & 30 \\
7 & 0.75 & 5 \\
8 & 0.75 & 15 \\
9 & 0.75 & 30 \\
$10^{*}$ & 0.50 & 15 \\
\hline
\end{tabular}

${ }^{*}$ The anisotropic sample configuration was used

Compression Test (UCT). Then, by trial-and-error, the set of parameters that yields the correct macroscopic behaviour in terms of compressive and tensile strength, elastic modulus as well as failure mode are chosen. As this topic has been explored extensively by other authors, see e.g. the local constitutive model approach in [33] or the calibration scheme in [50], the process of calibration was not in focus of this study. Instead, a simplified calibration approach was used. Since the study is not focusing on a specific material, properties consistent with a coarse grained granite [12] has been used. The elastic modulus and the Poisson's ratio were set to $60 \mathrm{GPa}$ and 0.2 , respectively, and a tensile strength between 10 and $14 \mathrm{MPa}$ was used. Since the bond stiffnesses and strengths were governed by the Weibull distribution, the calibration consisted of finding the corresponding scale parameters. A zero subscript denotes these scale parameters, e.g. the scale parameter for the bond normal strength is denoted $\bar{\sigma}_{c, 0}$.

In an effort to minimize the amount of trial-and-error calibration, the set of unknown parameters was decreased by utilizing analytical expressions and values from literature. For the normal stiffness of the DEM, Potyondy and Cundall [38] suggested

$k_{n}=4 R E_{c}$

where $R$ is the particle radius $E_{c}$ is the particle stiffness. In this work, the particle stiffness was set equal to the macroscopic elastic modulus, i.e. $E_{c}=60 \mathrm{GPa}$. Using elastic theory for the bulk and shear modulus [25], the ratio between the shear and normal stiffness for both the DEM and BPM was obtained as

$\frac{k_{s}}{k_{n}}=\frac{\overline{k_{s}}}{\overline{k_{n}}}=\frac{1}{2(1+v)}$

where $v$ is the Poisson's ratio. 
In the original BPM [38], two particles are bound together only if they are in direct contact. By increasing the interlocking range, however, the brittleness, i.e. tensile to compressive strength ratio, can be increased. As pointed out by Scholtés et. al [44], the interlocking range should be chosen with care to minimize the amount of particles embedded between interacting pairs of particles. In this study, using a uniform particle size throughout the body, the particles were allowed to be bounded with neighbouring particles within one particle diameter, i.e. by setting the interlocking range $\bar{\beta}=2 R$. This ensured that, for a given direction, the parent particle did not bound with more than one particle. Although some semiembedding was obtained, this interaction range resulted in an almost perfectly brittle fracture and was used for all simulations. In order to obtain quasi-static conditions, the damping coefficients $c_{n}$ and $c_{s}$ of the DEM were both set to 0.99 . In accordance with the work conducted by Potyondy and Cundall, a value of $\bar{\alpha}=0.7$ was used for the BPM damping, which is considered to be representative of quasi-static conditions for Lac du Bonnet granite [38]. For the particleparticle contact, a frictional parameter of $\mu_{p p}=0.50$ was used, while $\mu_{p j}=0.20$ was used for the particle-jaw contact.

With the above determined parameters, the mean normal stiffness $\bar{k}_{n, 0}$ was obtained by trial-and-error from the UCT. The sample was generated using the approach described in Sect. 2.3 with shape parameter $m=15$. For each cement strength ratio, a shape parameter $m=15$ was used to calibrate the strength values $\bar{\sigma}_{c, 0}$ and $\bar{\sigma}_{c, 0}$ for each cement scaling case. Following the approach used in [31], the mean bond shear strength was selected slightly above the limit for which shear failure at the loading jaws occurred. For the mean normal bond strength, several sets of 10 samples were simulated until an average predicted tensile strength of roughly $12 \mathrm{MPa}$ was obtained.

The final input parameters common for all three cement scaling factors are presented in Table 2. The mean normal bond strengths $\bar{\sigma}_{c, 0}$ were set to 8.21, 6.26 and $5.31 \mathrm{MPa}$ and the mean shear bond strengths were set to $114,87.0$ and $73.8 \mathrm{MPa}$ for $C_{f}=0.25, C_{f}=0.50$ and $C_{f}=0.75$, respectively. In Fig. 6, two examples of BDT measurements of a granite with elastic modulus $63 \mathrm{GPa}$ [52] are shown. Thus, the stiffness response of the current model, calibrated towards an elastic modulus of $60 \mathrm{GPa}$, is comparable to what can be seen for granitic rocks.

\section{Results and discussion}

In this section, the results from the numerical simulations of the generated samples are presented and discussed. The results originates from 10 samples per defined case, see Table 1. The performance of the proposed rock model is discussed and the crack initiation, propagation, coalescence
Table 2 Micromechanical parameters common for all simulations

\begin{tabular}{llc}
\hline Parameter & Units & Value \\
\hline$k_{n}$ & {$[\mathrm{kN} / \mathrm{mm}]$} & 24.0 \\
$k_{s} / k_{n}$ & {$[\mathrm{kN} / \mathrm{mm}]$} & 0.417 \\
$\bar{k}_{n, 0}$ & {$[\mathrm{GPa}]$} & 7.01 \\
$\bar{k}_{s, 0} / \bar{k}_{n, 0}$ & {$[\mathrm{GPa}]$} & 0.417 \\
$c_{n}$ & {$[-]$} & 0.99 \\
$c_{s}$ & {$[-]$} & 0.99 \\
$\bar{\alpha}$ & {$[-]$} & 0.70 \\
$\mu_{p p}$ & {$[-]$} & 0.50 \\
$\mu_{p j}$ & {$[-]$} & 0.20 \\
$\bar{\beta}$ & {$[\mathrm{mm}]$} & 0.20 \\
\hline
\end{tabular}

and branching as well as predicted tensile strength of the BDT is evaluated. The simulations were conducted using the LS-DYNA software, version R12. A total of 110 simulations were conducted of the 100 samples, with the anisotropic samples being simulated twice (once per load direction). The simulations were conducted using two Xeon Gold 6248R 3 $\mathrm{GHz}$ (96 total cores), resulting in a computational time of roughly $7 \mathrm{~h}$ per sample.

\subsection{Predicted tensile strength}

The tensile stress at the centre of the disc, as predicted by Eq. (1), versus loading jaw displacement is shown in Fig. 7. As can be deduced from Fig. 7a-c, a larger spread of predicted tensile strength was obtained for smaller values of the shape parameter. From the relative tensile strength standard deviation $(\sigma / \mu)$ presented in Table 3, it is also evident that, for a given shape parameter, weaker grain cementing tended to result in larger variations with regards to predicted tensile strength. In fact, this is true for all cases except for case $5\left(C_{f}=0.50\right)$ which has a smaller spread than case 8 $\left(C_{f}=0.75\right)$.

Also evident for all the cases in Fig. 7 is the high level of brittleness obtained, which is consistent with the choice of a rather large interlocking range $\bar{\beta}$ [44]. Further, some of the samples continued to carry load after the main fracture point due to the post-fracture loading of the two remaining semi-discs. Also, some of the samples exhibited a pre-failure load drop. This is most evident for case 3 in Fig. 7c, where one sample showed a significant load drop. By observing the damage patterns of these samples, it was concluded that these load drops were due to shear failure close to the loading jaws.

The predicted tensile strength and stiffness response, evaluated as $k=\sigma_{t} / d_{f}$, where $d_{f}$ is the displacement at failure, was found to increase with the shape parameter. This is reasonable since an increase in the shape parameter not only 
Table 3 Mean tensile strengths and relative standard deviation, mean failure displacement and stiffness for each of the nine cases

\begin{tabular}{|c|c|c|c|c|c|c|c|c|c|}
\hline Case & 1 & 2 & 3 & 4 & 5 & 6 & 7 & 8 & 9 \\
\hline $\begin{array}{l}\text { Mean tensile strength } \mu \\
{[\mathrm{MPa}]}\end{array}$ & 9.38 & 12.23 & 13.29 & 9.43 & 12.19 & 12.8 & 8.89 & 12.56 & 13.12 \\
\hline $\begin{array}{l}\text { Relative tensile strength } \\
\text { standard deviation SD } \\
{[\%]}\end{array}$ & 14.48 & 6.82 & 4.90 & 11.17 & 3.72 & 4.35 & 8.85 & 3.93 & 2.73 \\
\hline $\begin{array}{l}\text { Mean failure } \\
\quad \text { displacement } d_{f}[\mu \mathrm{m}]\end{array}$ & 47.77 & 54.47 & 57.03 & 48.24 & 54.31 & 54.79 & 45.32 & 55.34 & 55.59 \\
\hline Stiffness $k[\mathrm{kN} / \mu \mathrm{m}]$ & 196.15 & 224.37 & 232.85 & 195.04 & 224.38 & 234.04 & 195.93 & 227.00 & 236.05 \\
\hline
\end{tabular}

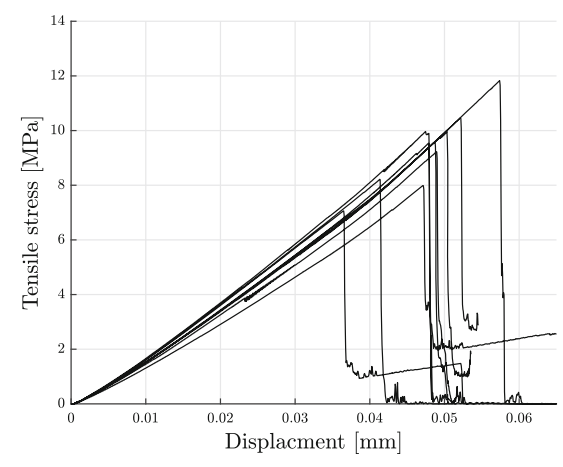

(a) Case 1: $C_{f}=0.25, m=5$.

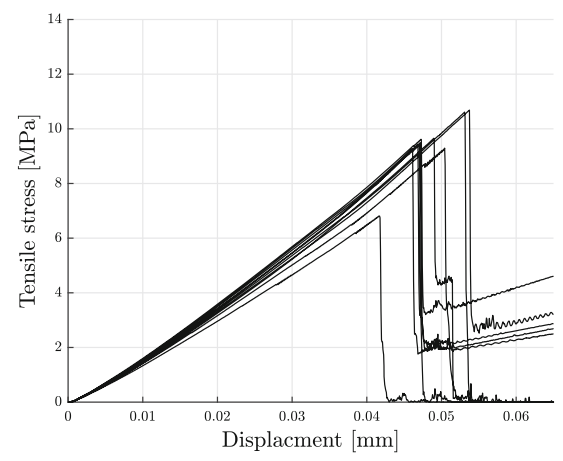

(d) Case 4: $C_{f}=0.50, m=5$.

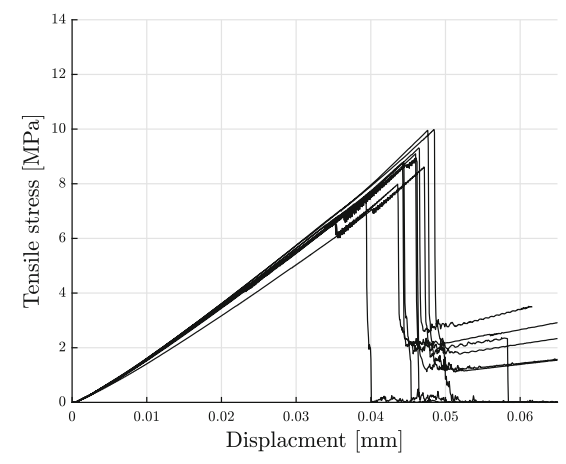

(g) Case 7: $C_{f}=0.75, m=5$.

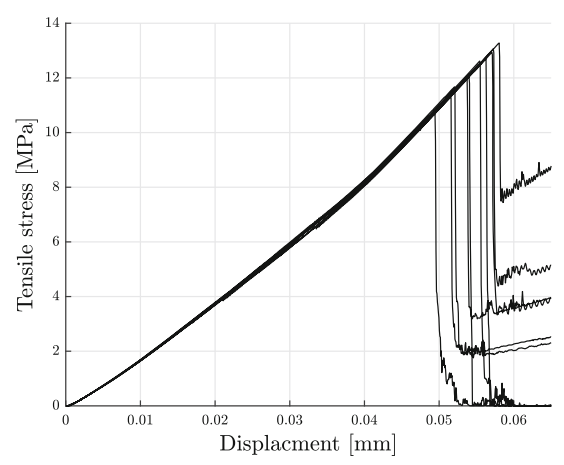

(b) Case 2: $C_{f}=0.25, m=15$.

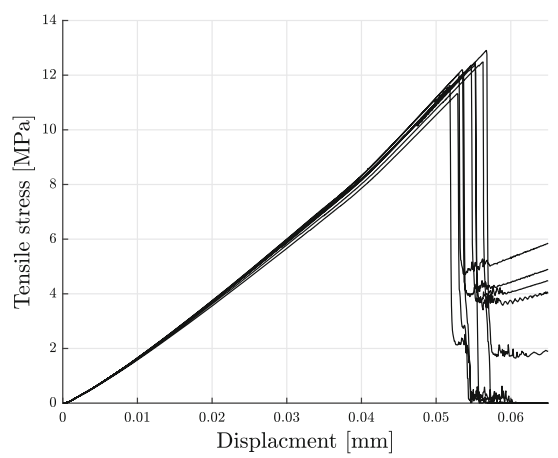

(e) Case 5: $C_{f}=0.50, m=15$.

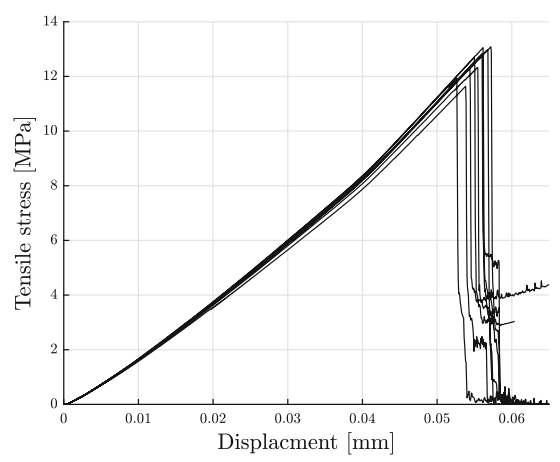

(h) Case 8: $C_{f}=0.75, m=15$.

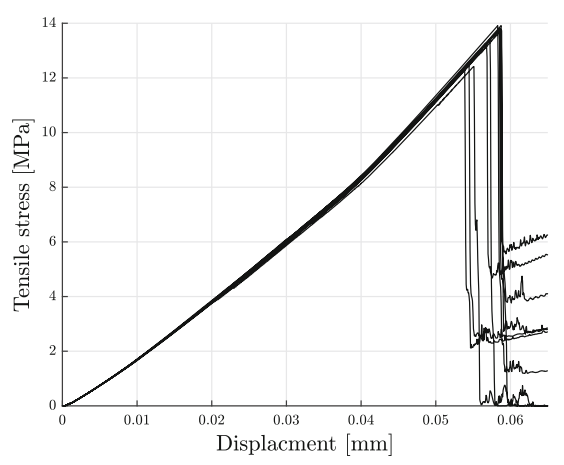

(c) Case 3: $C_{f}=0.25, m=30$.

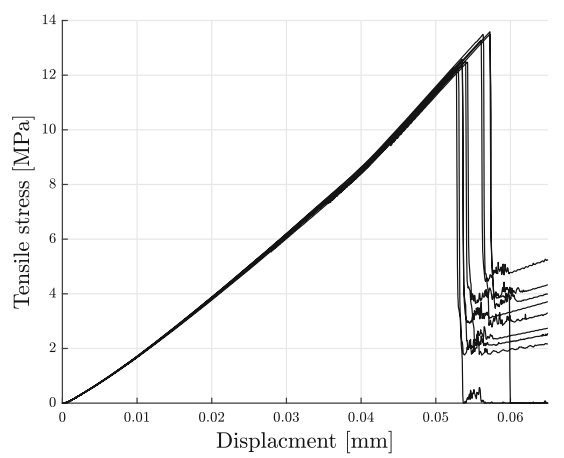

(f) Case 6: $C_{f}=0.50, m=30$.

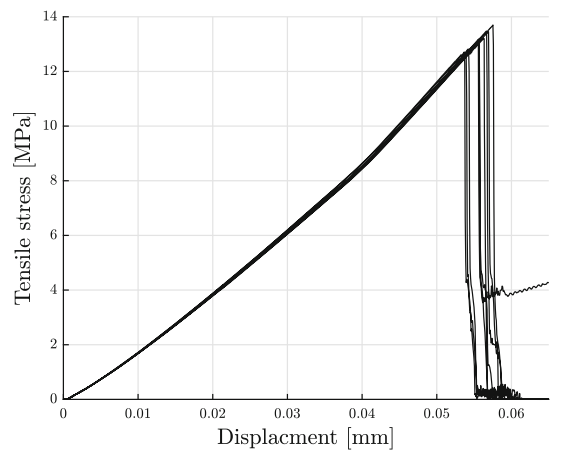

(i) Case 9: $C_{f}=0.75, m=30$.

Fig. 7 The tensile stress at the centre of the disc, as predicted from Eq. (1), versus loading jaw displacement for the nine combinations of cement scale factors $C_{f}=0.25,0.50,0.75$ and shape parameters $m=5,15,30$ 


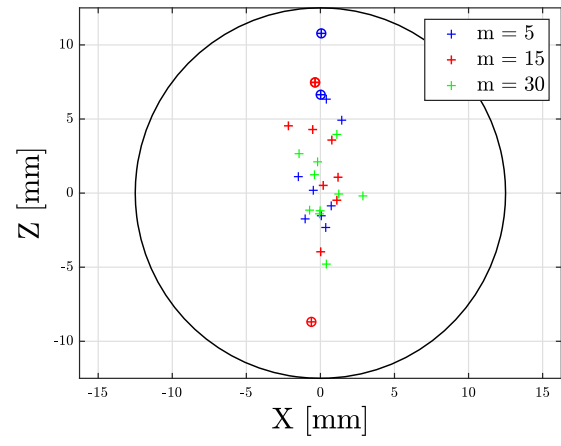

(a) $C_{f}=0.25$.

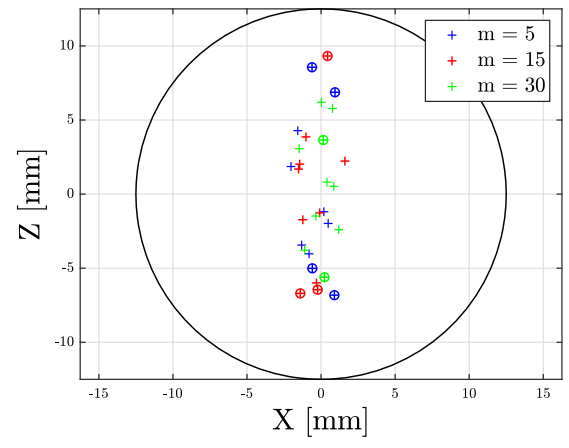

(b) $C_{f}=0.50$.

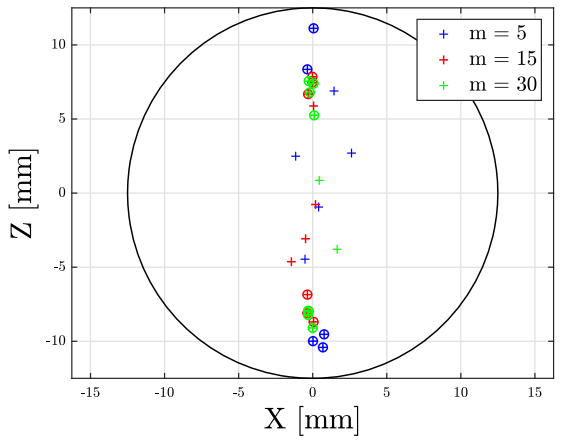

(c) $C_{f}=0.75$.

Fig. 8 Crack initiation points for the three cement scale factors $C_{f}$ and heterogeneity indices $m$. Markers enclosed by a circle denotes initiation from damage originating from loading jaws

decreases the heterogeneity, but also increases the mean value of the normal and shear stiffnesses.

\subsection{Crack initiation and propagation}

In this subsection, results regarding the effects that the shape parameter and cement strength have on the initiation and propagation of cracks of the BDT are presented and discussed. In the first subsection, the initiation point and the consequent validity of the BDT is evaluated and discussed. In the second subsection, the crack propagation of the radial and through-thickness directions is presented for a few selected samples.

\subsubsection{Initiation}

In Fig. 8, the initiation points for the three cement factors are shown. These points were defined as the point at which the rapid propagation of the splitting crack started. Further, the samples where the main crack initiated from damage, originating from the loading jaws were identified. Although these cracks originate from the loading jaws, the initiation points were placed at the point at which rapid propagation initiated.
As evident from Fig. 8 and Table 4, there exists a clear positive correlation between the cement strength and the amount of cracks initiating from the loading jaws. For the cement strength $C_{f}=0.25,16.7 \%$ of the cracks initiated from the loading jaws. The same is true for $30 \%$ and $63 \%$ of the samples for $C_{f}=0.50$ and $C_{f}=0.75$, respectively. By visual inspection of the damage onset, these cracks were found to initiate from a crushed zone directly underneath the loading jaws, which is consistent with experimental observations [17]. For the stronger cement strengths, this crushed zone tended to be more severe and prevalent, which could explain the positive correlation between cement strength and the amount of loading jaw cracks. Representative examples of the accumulated damage right before failure for the three cement strengths are shown in Fig. 9a-c. As observed from these figures, the crushed zones are more severe for stronger cement strengths where multiple cracks can be observed radiating from these zones. For the weaker cement strengths, cracks initiating from grain boundaries tended to be spread out around the vertical centre line of the disc.

In order for the BDT to be a valid method for measuring the tensile strength, the crack should initiate close to the central part of the disc, meaning that samples should be disregarded if the crack initiated from the loading jaws [6,28].
Table 4 Proportion of jaw cracks and normalized mean distance of initiation point from centre

\begin{tabular}{lllll}
\hline Case & Jaw cracks & mean $(|x|) / D[-]$ & mean $(|z|) / D[-]$ & $\left(\sqrt{x^{2}+z^{2}}\right) / D[-]$ \\
\hline 1 & $2 / 10$ & 0.030 & 0.095 & 0.104 \\
2 & $3 / 10$ & 0.034 & 0.105 & 0.116 \\
3 & 0.034 & 0.075 & 0.094 \\
4 & $0 / 10$ & 0.043 & 0.112 & 0.122 \\
5 & $4 / 10$ & 0.041 & 0.107 & 0.119 \\
6 & $3 / 10$ & 0.031 & 0.120 & 0.128 \\
7 & $2 / 10$ & 0.049 & 0.140 & 0.152 \\
8 & $5 / 10$ & 0.022 & 0.144 & 0.146 \\
9 & $6 / 10$ & 0.042 & 0.093 & 0.102 \\
\hline
\end{tabular}




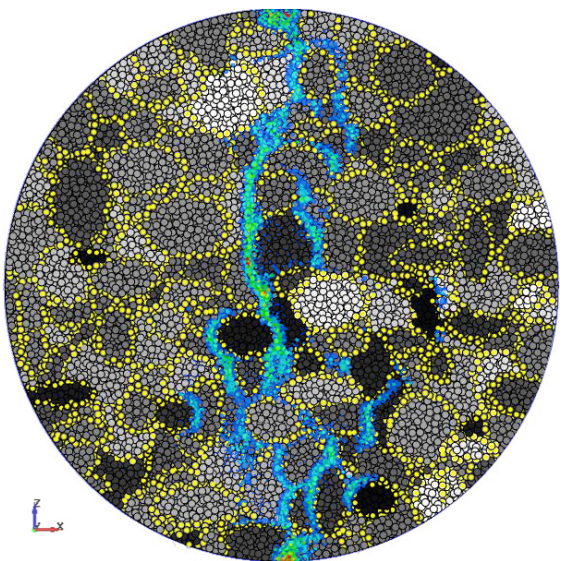

(a) Before failure $C_{f}=0.25, m=5$.

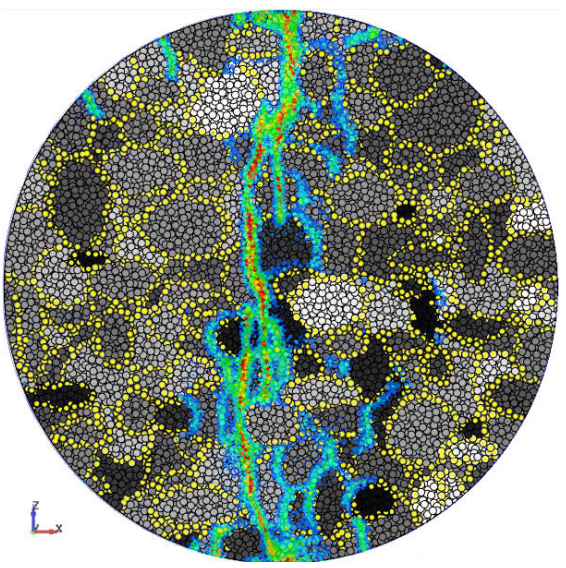

(d) After failure $C_{f}=0.25, m=5$.

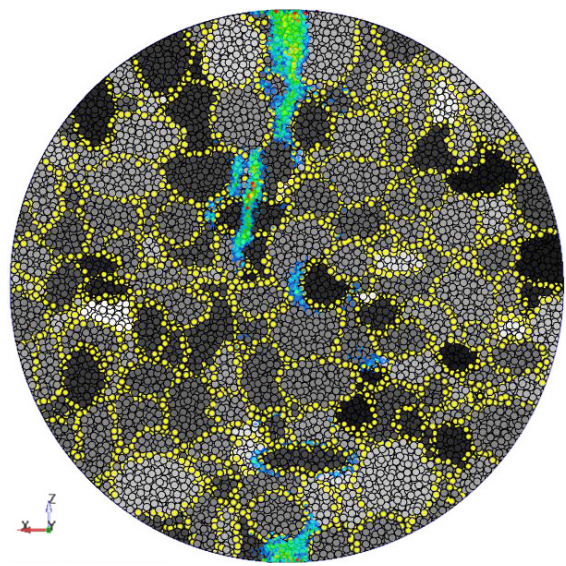

(b) Before failure $C_{f}=0.50, m=5$.

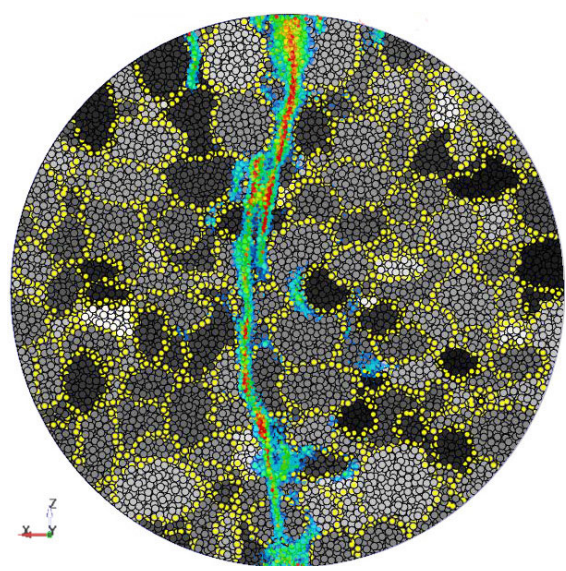

(e) After failure $C_{f}=0.50, m=5$.

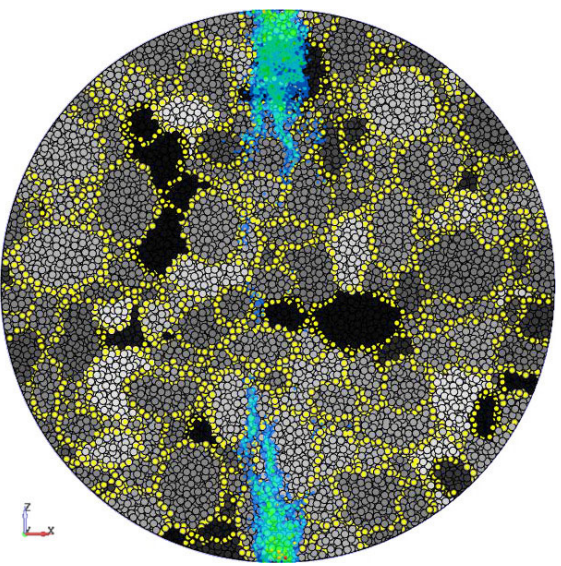

(c) Before failure $C_{f}=0.75, m=30$.

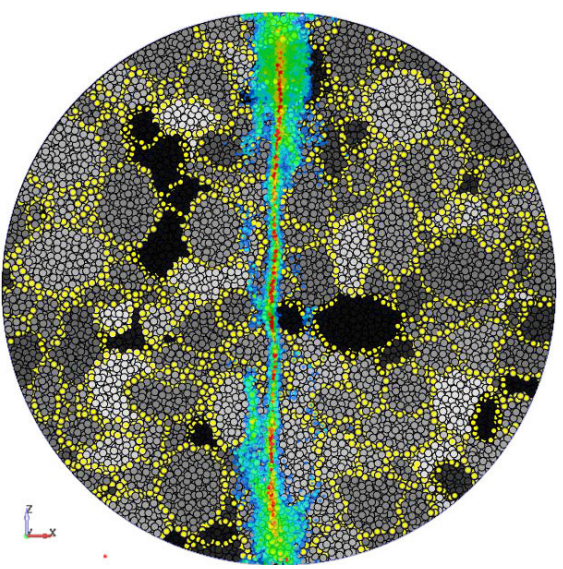

(f) After failure $C_{f}=0.75, m=30$.
Fig. 9 Examples of accumulated damage right before failure for different heterogeneity indices and cement scale factors $C_{f}=0.25$ (a), $C_{f}=0.25(\mathbf{b})$ and $C_{f}=0.25(\mathbf{c})$, and the corresponding final crack

Further, the distance from the centre where the crack initiates should not be too large. Although no clear distinctions are available regarding the allowed deviation from the centre, the distance speaks to the validity of the test. To this end, the mean distance from the centre at which the crack initiated were evaluated for each case (with tests where cracks initiated from loading jaws being disregarded), see Table 4. Note that the distances in Table 4 are normalized with sample diameter $D$. If case 9 is disregarded (due to only having 2 valid tests), the normalized initiation distance increases slightly with increased cement strength. This suggests that the BDT is more appropriate, i.e. Eq. (1) yields a more accurate prediction of the tensile strength, for samples with lower cement strengths.

\subsubsection{Propagation}

As mentioned in the previous section, damage accumulates around the vertical centre line of the sample for the lower paths $(\mathbf{d}-\mathbf{f})$. Particle colour represents the loss of bonds, i.e. a red particle has loss all of its bonds while the bonds of a blue particle remains intact

cement strength,. This is further shown in Fig. 10, where a few stages of the crack propagation for $C_{f}=0.25$ (case 2) are shown. The main crack initiates from this accumulated damage on the sample surface (Fig. 10a, b), and tends to propagate along the direction giving the shortest distance to a free surface [54]. As there are two free surfaces, i.e. the sample perimeter and the opposite flat sample surface, one would expect the crack to propagate along these directions. This hypothesis is supported by the propagation path in Fig. 10b-d, where the crack propagates along the vertical direction towards both the loading jaws and along the through-thickness direction. Further, the zigzag pattern observed for this case was typical for the cases with low cement strength as the crack tended to branch and propagate through the weak grain boundaries. Another case of $C_{f}=0.25$ (case 1), with a lower shape parameter $m=5$, is shown in Fig. 9d. As can be seen from this case, which can be considered heavily heterogeneous, the amount of zigzag and branching of the crack path is more severe. This is a trend that 

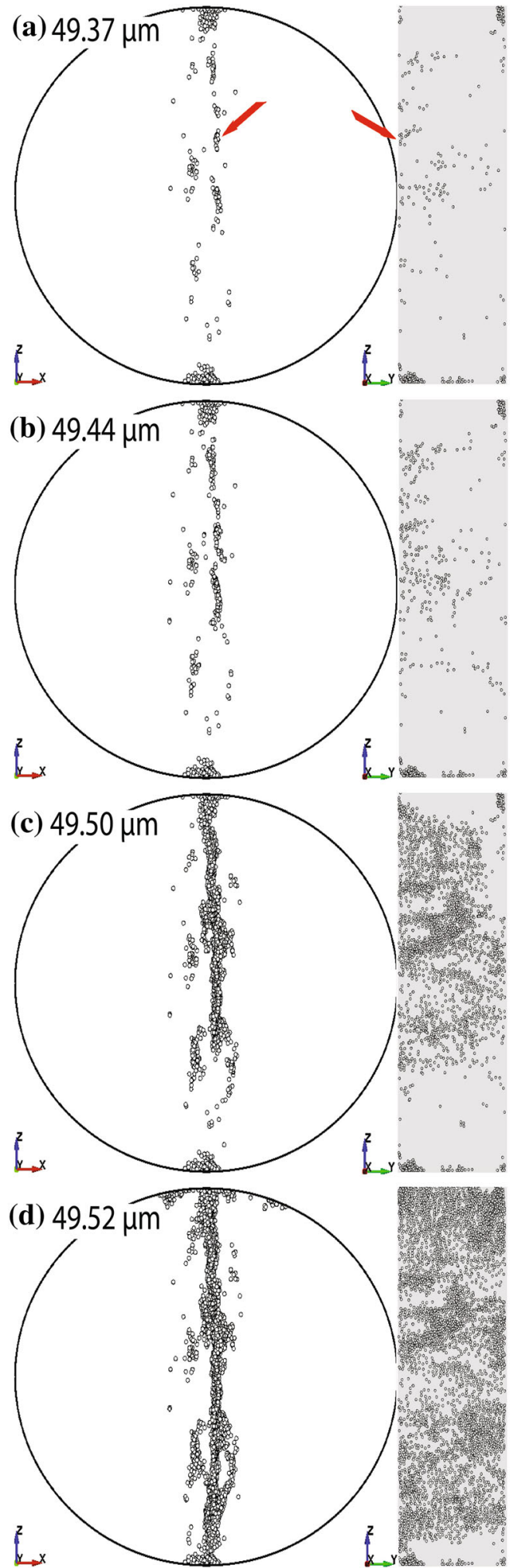

Fig. 10 Crack propagation of the vertical and through-thickness direction at four selected stages of jaw displacements from a sample from case 2 (cement scaling factor $C_{f}=0.25$ and heterogeneity index $m=15$ ). The crack initiates slightly above and to the right of the centre of the disc (a), rapid crack propagation through-thickness and towards both loading jaws $(\mathbf{b}, \mathbf{c})$ and the fully propagated primary crack (d)
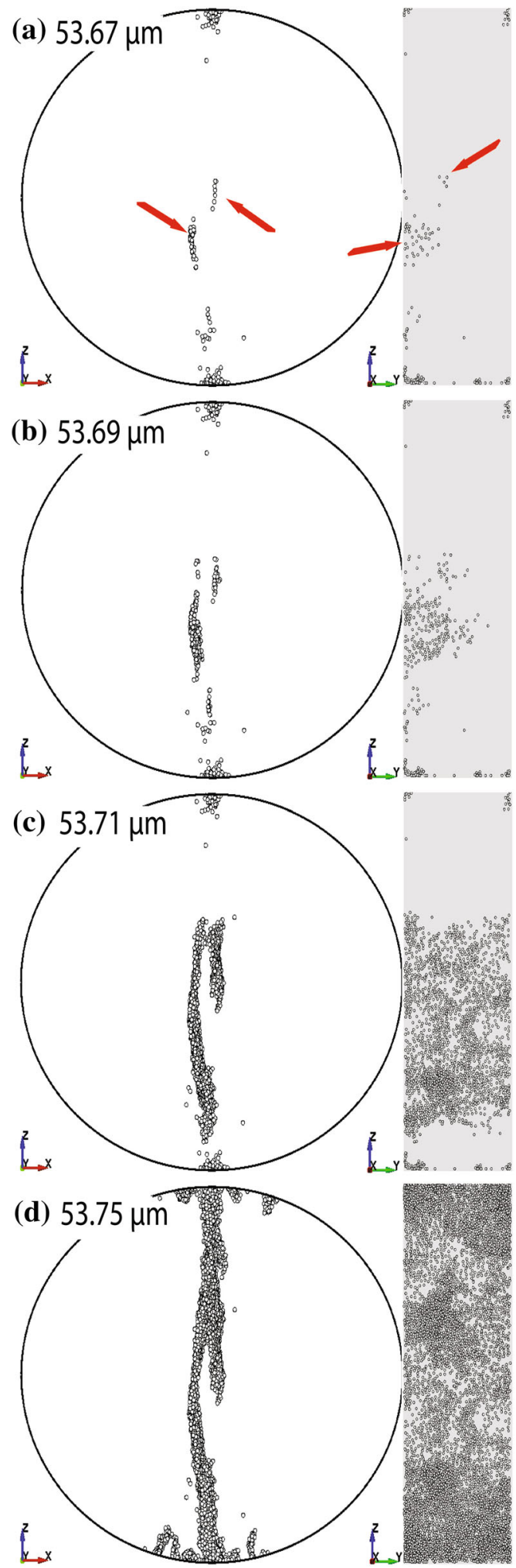

Fig. 11 Crack propagation of the vertical and through-thickness direction at four selected stages of jaw displacements from a sample from case 5 (cement scaling factor $C_{f}=0.50$ and heterogeneity index $m=15$ ). The crack initiates slightly below and to the left of the centre of the disc (a), rapid crack propagation through-thickness and towards both loading jaws (b, c) and the fully propagated primary crack (d) 

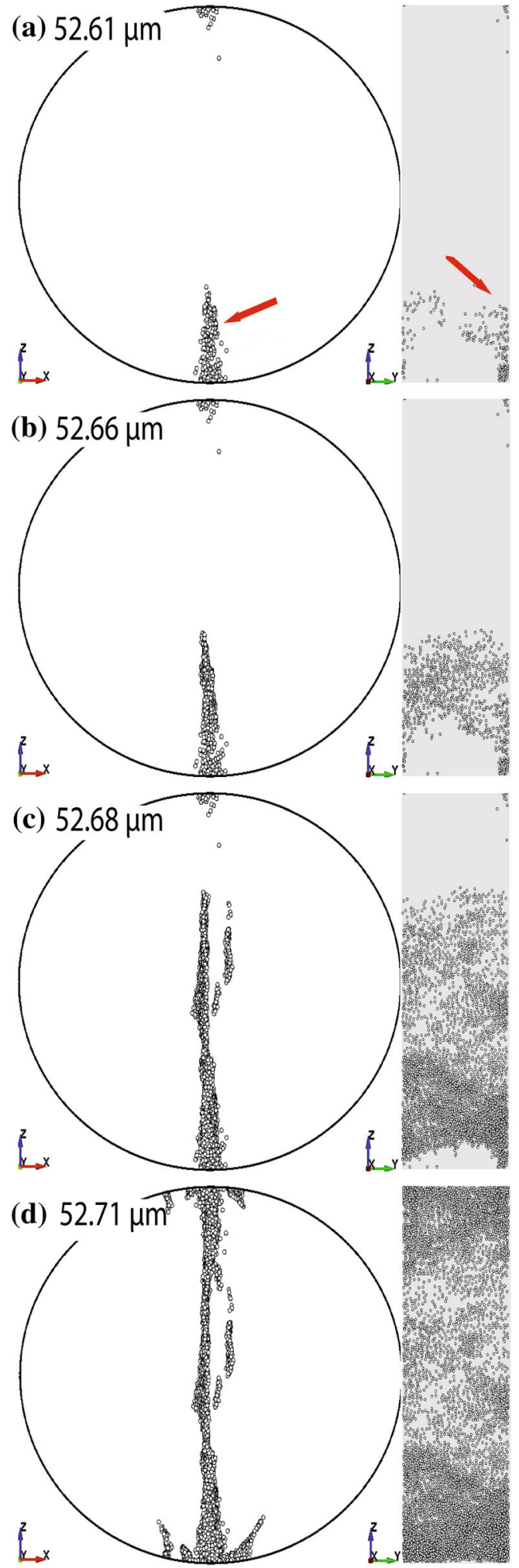

Fig. 12 Crack propagation of the vertical and through-thickness direction at four selected stages of jaw displacements from a sample from case 8 (cement scaling factor $C_{f}=0.75$ and heterogeneity index $m=15$ ). The crack initiates from surface cracks originating from the loading jaw (a), rapid crack propagation through-thickness and towards the top jaw $(\mathbf{b}, \mathbf{c})$ and the fully propagated primary crack $(\mathbf{d})$ was observed for all cement strength cases, i.e. that amount of zigzag and branching increased with heterogeneity.

In contrast, for the higher cement strength $C_{f}=0.50$ (case 5) in Fig. 11, the crack path did not experience as severe of a zigzag pattern. Further, the pre-failure accumulated damage is also less severe. From Fig. 11a, it can be seen that two major cracks initiated close to the centre of the disc. Both of the cracks can then be seen to propagate and coalesce in Fig. 11b, c. After coalescing, the leftmost crack becomes dominating, halting the propagation of the rightmost crack which produces the final crack path in Fig. 11d.

The two aforementioned cases are examples of valid tests, i.e. the main cracks initiated close to the centre part of the disc. An example of an invalid test from $C_{f}=0.75$ (case 8) can be seen in Fig. 12. Aside from the crushed zones at the loading jaws, no other damage was accumulated within this sample. The crack initiated from the crushed zone at the lower jaw, Fig. 12a, and propagated along the vertical direction towards the upper jaw, Fig. 12b-c. Here, a case of crack branching can be observed close to the centre part of the disc, which then coalesce with the main crack in Fig. 12d.

Although a few samples had major cracks initiating within the sample, such as the rightmost crack in Fig. 11, the vast majority of samples had major crack initiation at one of the flat free surfaces. Given a surface crack on one of the free, flat surfaces of the sample, it would be reasonable to assume that the crack will propagate straight through the sample and appear at a position coinciding with the initiation position since this is the shortest path to a free surface. This was the case for the majority of cases, examples being the samples in Figs. 11 and 12. However, the through-thickness propagation path was found to deviate from a straight through-thickness path for a few cases, as can be seen in Fig. 10. This fact suggest that both sample surfaces should be observed when conducting a BDT, as to not mistake a surfacing throughthickness crack with the initiation point.

By loading a sample after the main splitting crack has fully propagated, the initiation of secondary cracks as well as branching and coalescence of these cracks can be evaluated. In Figs. 13 and 14, a few selected stages of the post-failure crack propagation of two samples are shown. As soon as the main splitting crack has fully propagated, secondary cracks are initiated at the loading jaws. The amount of secondary cracks varied due to inhomogeneities, but typically four secondary cracks could be observed at each loading jaw. Further, the path of these secondary cracks tended to exhibit a parabolic form and be fairly symmetrical across the vertical direction, e.g. as shown in Fig. 13, which is consistent with experimental and numerical observations $[6,9,11,19]$. However, unsymmetrical secondary cracks were also observed, such as the case in Fig. 14. Here, the secondary cracks on the right side coalesce early on with the main crack and does not propagate far throughout the sample, while the secondary 


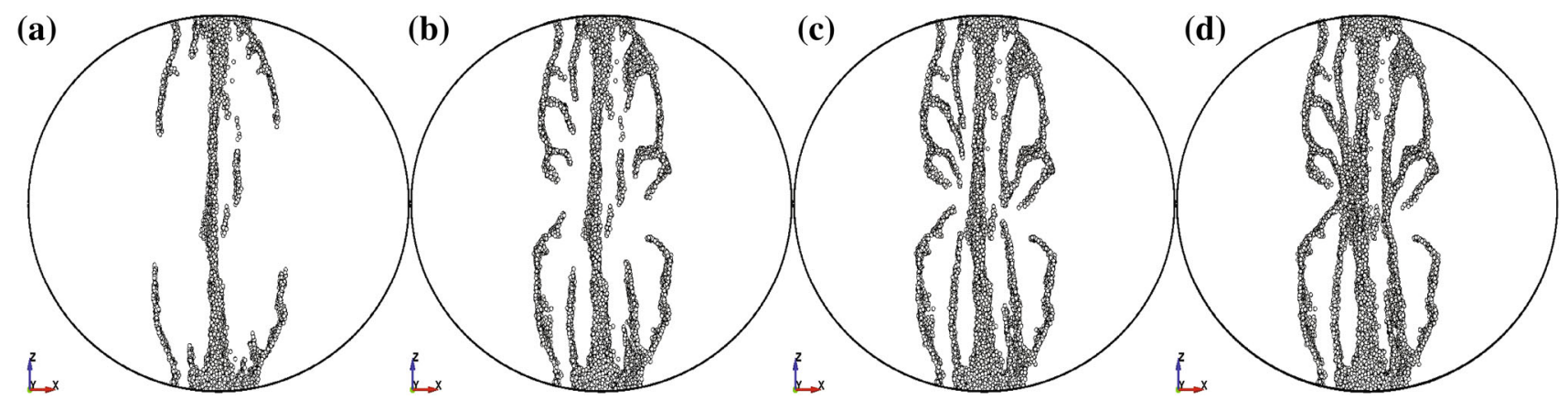

Fig. 13 The post-failure crack propagation of the sample from case 8 (cement scaling factor $C_{f}=0.75$ and heterogeneity index $m=15$ ). The initiation of secondary cracks main splitting crack has fully propagated (a) and the propagation, branching and coalescence of these secondary cracks $(\mathbf{b}-\mathbf{d})$

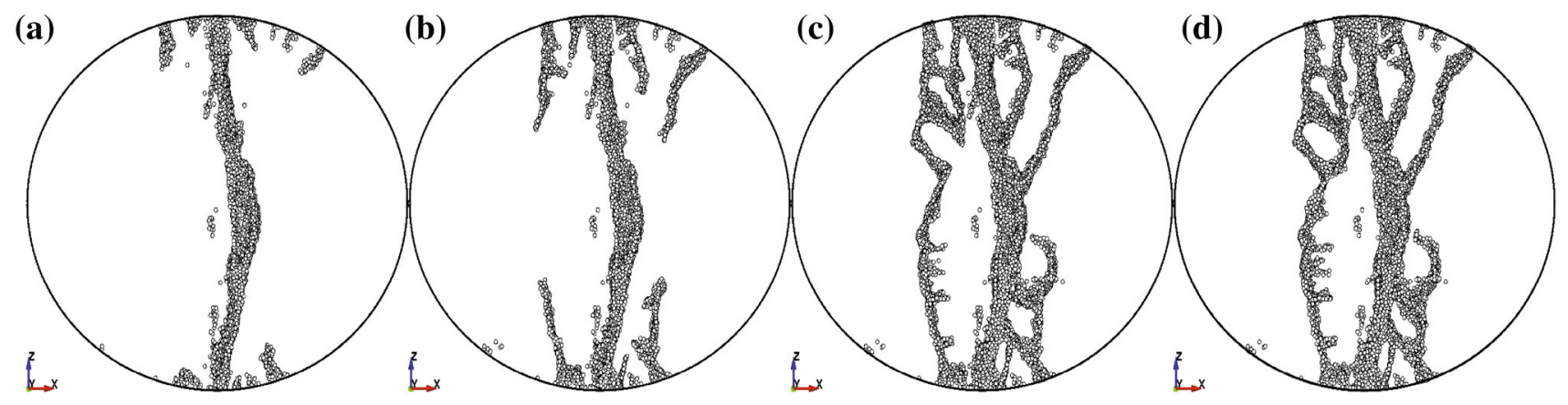

Fig. 14 The post-failure crack propagation of a sample from case 5 (cement scaling factor $C_{f}=0.50$ and heterogeneity index $m=15$ ). The initiation of secondary cracks main splitting crack has fully propagated (a) and the propagation, branching and coalescence of these secondary cracks $(\mathbf{b}-\mathbf{d})$

cracks on the left side does not coalesce with the main crack at all. A reasonable explanation to this has to do with the fact that the crack tends to propagate along paths that yields the shortest distance to a free surface [54]. For the secondary cracks on the right side, the main splitting crack corresponds to the free surface towards which the crack propagates.

\subsection{Anisotropy}

The force versus displacement of the 10 anisotropic samples (case 10) is shown in Fig. 15. The samples were simulated two times, once with loading applied along the $z$-direction, perpendicular to the preferred grain direction, and once with the load applied along the $x$-direction, parallel to the preferred grain direction. Clearly, the predicted tensile strength when loading within the $x$-direction is lower than the predicted strength when the load is applied along the $z$-direction. On average, the predicted tensile strength when loading parallel to the preferred grain direction is $79.10 \%$ of the strength of the other direction. This can be explained by the fact that the crack is more likely to propagate along the weak grain boundaries when the loading is applied parallel to the preferred grain direction [47]. An example of this can be seen in Fig. 16, where the final crack paths of both loading directions

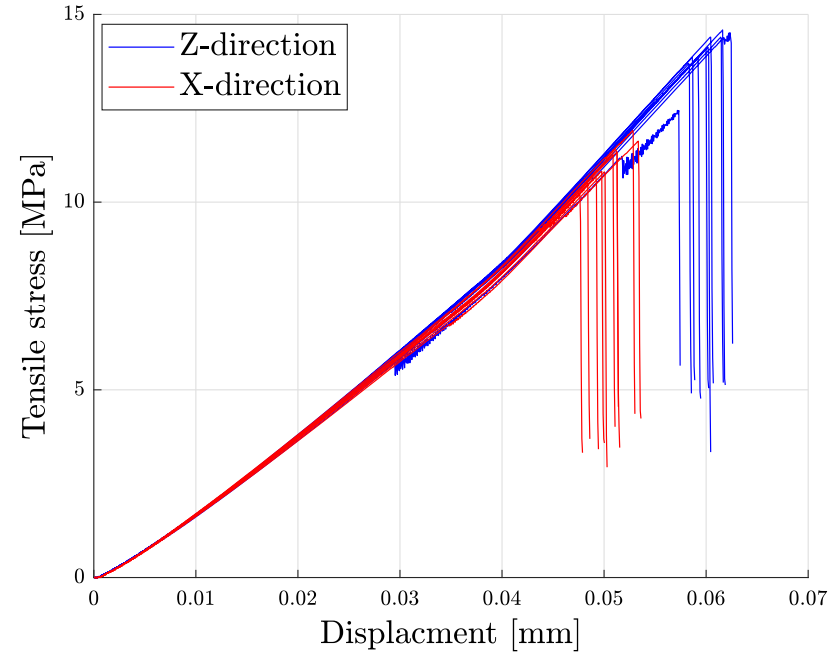

Fig. 15 Force versus jaw displacement for each loading direction of the five anisotropic samples

for one of the anisotropic samples are shown. When loading parallel to the preferred grain direction, the majority of the crack path coincides with the weak grain boundaries since the crack tends to propagate along a path of least resistance. In contrast, when loading perpendicular to the preferred grain 


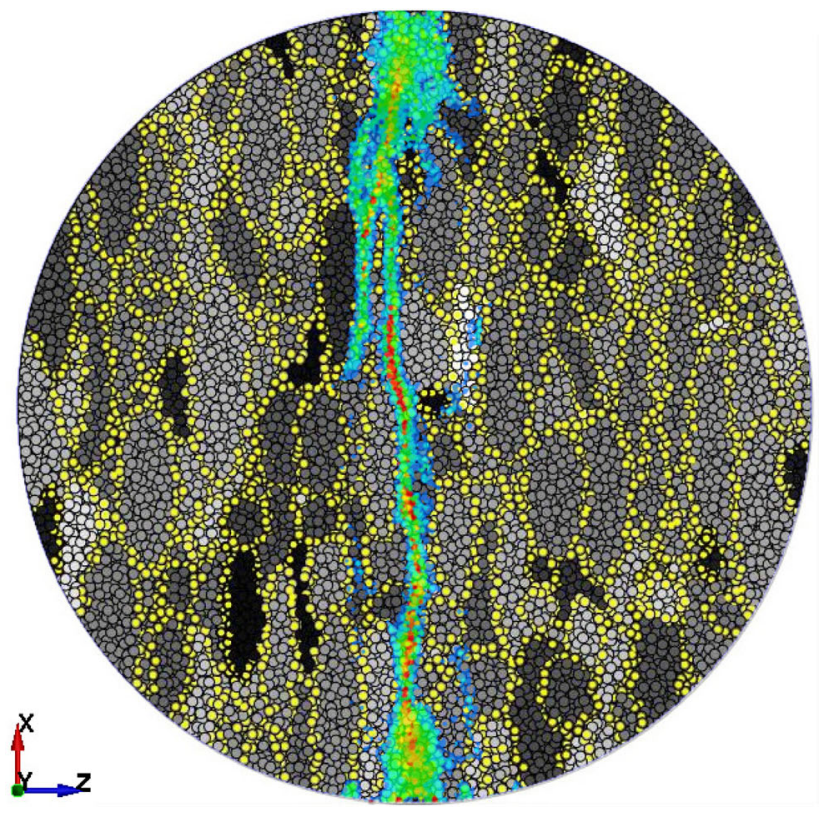

(a) Loading parallel to the preferred grain direction.

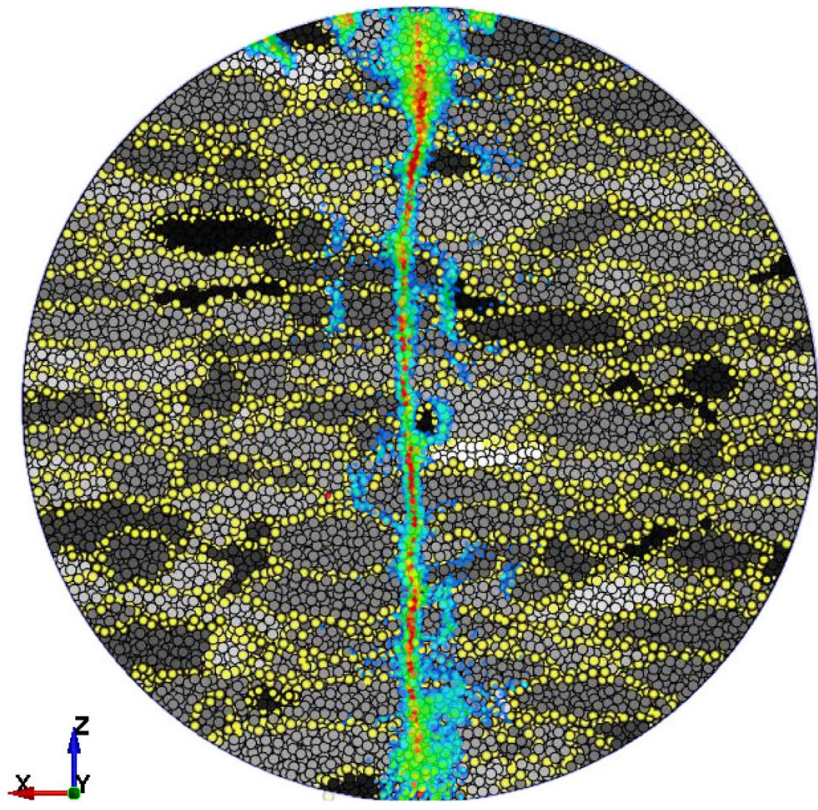

(b) Loading perpendicular to the preferred grain direction.

Fig. 16 The resulting splitting crack for one of the anisotropic samples when loading within the $z$-direction (a) and loading along the $x$-direction (b)

direction the crack path propagates across grains more frequently.

\section{Conclusion}

In this study, a new approach for modelling brittle heterogeneous materials was proposed and used to study the Brazilian Disc Test. The heterogeneity of the material was introduced by random, irregular grain shapes and micromechanical parameters that were governed by the Weibull distribution. By generating and simulating a large set of samples, the variations introduced by the stochastic nature of the model was evaluated in terms of predicted tensile strength as well as crack initiation, propagation, coalescence and branching. In conclusion:

- The proposed numerical model is able to capture different levels of unpredictability of brittle heterogeneous materials. This is true for the predicted tensile strength and stiffness as well as the crack properties, all of which can be governed with the model parameters.

- The results show that a wide range of behaviours consistent with literature can be obtained with the proposed numerical approach.

- The model gave new insights regarding the initiation and propagation of cracks of the Brazilian disc test. The results indicate that the crack does not always propagate along the shortest path to a free surface and the test is less suitable for materials with a high cement strength.

- The results show that the cement strength greatly affects the results in the Brazilian disc test. This is true regarding the initiation and propagation of the main splitting crack as well as the spread of the results. Furthermore, the crack paths are governed by the orientation and shape of the grains, more so for lower cement strengths.

- The grain generation process is able to generate irregular and anisotropic grain shapes that yield significantly different results along different loading directions.

- Although the present study was conducted on a microscopic scale, the proposed model can be applied to model brittle heterogeneous materials at a larger scale, for example in order to model the varying ground materials of rock drilling.

Acknowledgements This study is a part of the H2020-Project GEOFIT, which is acknowledged for financial support, Grant agreement Number 792210

Funding Open access funding provided by Lulea University of Technology.

\section{Declarations}

Conflict of interest The authors states that there is no conflict of interest regarding the contents of this study. 
Open Access This article is licensed under a Creative Commons Attribution 4.0 International License, which permits use, sharing, adaptation, distribution and reproduction in any medium or format, as long as you give appropriate credit to the original author(s) and the source, provide a link to the Creative Commons licence, and indicate if changes were made. The images or other third party material in this article are included in the article's Creative Commons licence, unless indicated otherwise in a credit line to the material. If material is not included in the article's Creative Commons licence and your intended use is not permitted by statutory regulation or exceeds the permitted use, you will need to obtain permission directly from the copyright holder. To view a copy of this licence, visit http://creativecomm ons.org/licenses/by/4.0/.

\section{References}

1. ASTM (2016) Standard test method for splitting tensile strength of intact rock core specimens. https://doi.org/10.1520/D3967-16

2. Bieniawski ZT, Hawkes I (1978) Suggested methods for determining tensile strength of rock materials. Int J Rock Mech Min Sci Geomech Abstr 15(3):99-103. https://doi.org/10.1016/01489062(78)90003-7

3. Carneiro (1943) A new method to determine the tensile strength of concrete. In: Presented at the proceedings of the 5th meeting of the Brazilian Association for technical rules

4. Cho N, Martin D, Sego DA (2007) Clumped particle model for rock. Int J Rock Mech Min Sci 44:997-1010. https://doi.org/10. 1016/j.ijrmms.2007.02.002

5. Cleary P (2004) Large scale industrial DEM modeling. Eng Comput 21:169-204. https://doi.org/10.1108/02644400410519730

6. Colback P (1966) An analysis of brittle fracture initiation and propagation in the Brazilian test. In: 1st ISRM congress

7. Cundall PA (1971) A computer model for simulating progressive, large-scale movements in blocky rock systems

8. Cundall PA, Strack ODL (1979) A discrete numerical model for granular assemblies. Géotechnique 29(1):47-65. https://doi.org/ 10.1680/geot.1979.29.1.47

9. Fahad M (1996) Stresses and failure in the diametral compression test. J Mater Sci 31:3723-3729. https://doi.org/10.1016/S0266352X(03)00015-6

10. Fairhurst C (1964) On the validity of the 'Brazilian' test for brittle materials. Int J Rock Mech Min Sci Geomech Abstr 1(4):535-546. https://doi.org/10.1016/0148-9062(64)90060-9

11. Hamdi P, Stead D, Elmo D (2014) Damage characterization during laboratory strength testing: a 3d-finite-discrete element approach. Comput Geotech 60:33-46. https://doi.org/10.1016/j. compgeo.2014.03.011

12. Hokka M, Black J, Tkalich D, Fourmeau M, Kane A, Hoang H, Li C, Chen W, Kuokkala VT (2016) Effects of strain rate and confining pressure on the compressive behavior of kuru granite. Int J Impact Eng. https://doi.org/10.1016/j.ijimpeng.2016.01.010

13. Hondros G (1959) The evaluation of Poisson's ratio and the modulus of materials of low tensile resistance by the Brazilian (indirect tensile) test with particular reference to concrete. Aust J Appl Sci 10(3):243-268

14. Hu X, Xie N, Zhu Q, Chen L, Li P (2020) Modeling damage evolution in heterogeneous granite using digital image-based grain-based model. Rock Mech Rock Eng. https://doi.org/10.1007/ s00603-020-02191-3

15. Huang H, Detournay E (2013) Discrete element modeling of toolrock interaction ii: rock indentation. Int $\mathrm{J}$ Numer Anal Meth Geomech. https://doi.org/10.1002/nag.2114
16. Huang H, Lecampion B, Detournay E (2013) Discrete element modeling of tool-rock interaction i: rock cutting. Int J Numer Anal Meth Geomech 37:1913-1929. https://doi.org/10.1002/nag.2113

17. Hudson J, Brown E, Rummel F (1972) The controlled failure of rock discs and rings loaded in diametral compression. Int J Rock Mech Min Sci Geomech Abstr 9(2):241-248. https://doi.org/10. 1016/0148-9062(72)90025-3

18. Ivars DM, Potyondy DO, Group IC (2015) The smooth-joint contact model. In: 8th world congress on computational mechanics (WCCM8), pp 29-31

19. Jiang H, Meng D (2018) 3d numerical modelling of rock fracture with a hybrid finite and cohesive element method. Eng Fract Mech. https://doi.org/10.1016/j.engfracmech.2018.05.037

20. Jonsén P, Hammarberg S, Pålsson B, Lindkvist G (2019) Preliminary validation of a new way to model physical interactions between pulp, charge and mill structure in tumbling mills. Miner Eng 130:76-84. https://doi.org/10.1016/j.mineng.2018.10.013

21. Jonsén P, Häggblad H, Sommer K (2007) Tensile strength and fracture energy of pressed metal powder by diametral compression test. Powder Technol 176(2):148-155. https://doi.org/10.1016/j. powtec.2007.02.030

22. Jonsén P, Åke Häggblad H, Gustafsson G (2015) Modelling the non-linear elastic behaviour and fracture of metal powder compacts. Powder Technol 284:496-503. https://doi.org/10.1016/j. powtec.2015.07.031

23. Jonsén P, Pålsson B, Stener J, Häggblad HK (2014) A novel method for modelling of interactions between pulp, charge and mill structure in tumbling mills. Miner Eng 63:65-72. https://doi.org/10. 1016/j.mineng.2013.12.005

24. Karajan N, Han Z, Teng H, Wang J (2014) On the parameter estimation for the discrete-element method in LS-DYNA ${ }^{\circledR}$. In: 13th international LS-DYNA users conference, pp 1-9

25. Kudryavtsev O, Sapozhnikov S (2016) Numerical simulations of ceramic target subjected to ballistic impact using combined dem/fem approach. Int J Mech Sci 114:60-70. https://doi.org/10. 1016/j.ijmecsci.2016.04.019

26. Larsson S, Pålsson BI, Parian M, Jonsén P (2020) A novel approach for modelling of physical interactions between slurry, grinding media and mill structure in wet stirred media mills. Miner Eng 148:106180. https://doi.org/10.1016/j.mineng.2019.106180

27. Larsson S, Rodríguez Prieto J, Heiskari H, Jonsén P (2021) A novel particle-based approach for modeling a wet vertical stirred media mill. Minerals 11:55. https://doi.org/10.3390/min11010055

28. Li D, Wong L (2012) The Brazilian disc test for rock mechanics applications: review and new insights. Rock Mech Rock Eng. https://doi.org/10.1007/s00603-012-0257-7

29. Li X, Zhang Q, Li H, Zhao J (2018) Grain-based discrete element method (GB-DEM) modelling of multi-scale fracturing in rocks under dynamic loading. Rock Mech Rock Eng. https://doi.org/10. 1007/s00603-018-1566-2

30. LSTC (2020) LS-Dyna keyword user's manual volume 1 (R12). Livermore Software Technology Corporation I

31. Ma Y, Huang H (2018) Dem analysis of failure mechanisms in the intact Brazilian test. Int J Rock Mech Min Sci 102:109-119. https://doi.org/10.1016/j.ijrmms.2017.11.010

32. Mellor M, Hawkes I (1971) Measurement of tensile strength by diametral compression of discs and annuli. Eng Geol 5(3):173225. https://doi.org/10.1016/0013-7952(71)90001-9

33. Oñate E, Zarate F, Miquel J, Isach MS, Celigueta M, Arrufat F, Gandikota R, Valiullin K, Ring L (2015) A local constitutive model for the discrete element method. Application to geomaterials and concrete. Comput Part Mech. https://doi.org/10.1007/s40571-0150044-9

34. Olsson E, Jelagin D, Forquin P (2019) Computational framework for analysis of contact-induced damage in brittle rocks. Int J Solids Struct. https://doi.org/10.1016/j.ijsolstr.2019.03.001 
35. Peng J, Wong L, Teh C (2017) Influence of grain size heterogeneity on strength and micro-cracking behavior of crystalline rocks. J Geophys Res Solid Earth. https://doi.org/10.1002/2016JB013469

36. Pitangueira RL, Silva RRE (2002) Numerical characterization of concrete heterogeneity. Mater Res 5(3):309-314. https://doi.org/ 10.1590/s1516-14392002000300015

37. Potyondy D (2010) A grain-based model for rock: approaching the true microstructure

38. Potyondy D, Cundall P (2004) A bonded-particle model for rock. Int J Rock Mech Min Sci 41:1329-1364. https://doi.org/10.1016/ j.ijrmms.2004.09.011

39. Rojek J (2014) Discrete element thermomechanical modelling of rock cutting with valuation of tool wear. Comput Part Mech 1:7184. https://doi.org/10.1007/s40571-014-0008-5

40. Rojek J, Oñate E, Labra C, Kargl H (2011) Discrete element modelling of rock cutting. Part Based Methods 25:247-267. https://doi. org/10.1007/978-94-007-0735-1_10

41. Saadati M, Forquin P, Weddfelt K, Larsson P (2016) On the tensile strength of granite at high strain rates considering the influence from preexisting cracks. Adv Mater Sci Eng 2016:1-9. https://doi. org/10.1155/2016/6279571

42. Saadati M, Forquin P, Weddfelt K, Larsson P, Hild F (2014) Granite rock fragmentation at percussive drilling-experimental and numerical investigation. Int J Numer Anal Meth Geomech. https:// doi.org/10.1002/nag.2235

43. Saksala T, Jabareen M (2019) Numerical modeling of rock failure under dynamic loading with polygonal elements. Int J Numer Anal Meth Geomech. https://doi.org/10.1002/nag.2947

44. Scholtès L, Donze F (2013) A dem model for soft and hard rocks: role of grain interlocking on strength. J Mech Phys Solids 61:352369. https://doi.org/10.1016/j.jmps.2012.10.005

45. Shamy UE, Civil NZ (2012) Discrete element method simulations of the seismic response of shallow foundations including soil-foundation-structure interaction. Int J Numer Anal Methods Geomech 36(2013):1303-1329. https://doi.org/10.1002/nag

46. Swab J, Yu J, Gamble R, Kilczewski S (2011) Analysis of the diametral compression method for determining the tensile strength of transparent magnesium aluminate spinel. Int J Fract. https://doi. org/10.1007/s10704-011-9655-1
47. Tianshou M, Peng N, Zhu Z, Zhang Q, Yang C, Zhao J (2018) Brazilian tensile strength of anisotropic rocks: review and new insights. Energies 11:304. https://doi.org/10.3390/en11020304

48. Ubach PA, Arrufat F, Ring L, Gandikota R, Zárate F, Oñate E (2016) Application of an enhanced discrete element method to oil and gas drilling processes. Comput Part Mech 3(1):29-41. https://doi.org/ 10.1007/s40571-015-0080-5

49. Wang P, Gao N, Ji K, Stewart L, Arson C (2019) Dem analysis on the role of aggregates on concrete strength. Comput Geotech 119:103290. https://doi.org/10.1016/j.compgeo.2019.103290

50. Wang Y, Tonon F (2009) Modeling lac du bonnet granite using a discrete element model. Int J Rock Mech Min Sci 46:1124-1135. https://doi.org/10.1016/j.ijrmms.2009.05.008

51. Weibull W (1951) A statistical distribution function of wide applicability. J Appl Mech 18:293-297

52. Wessling A (2021) Towards discrete element modelling of rock drilling. Licenciate thesis, pp 11-12. Luleå University of Technology

53. Xu G, He C, Chen Z, Wu D (2018) Effects of the micro-structure and micro-parameters on the mechanical behaviour of transversely isotropic rock in Brazilian tests. Acta Geotech 13(4):887-910. https://doi.org/10.1007/s11440-018-0636-7

54. Yanagidani T, Sano O, Terada M, Ito I (1978) The observation of cracks propagating in diametrically-compressed rock discs. Int $\mathrm{J}$ Rock Mech Min Sci Geomech Abstr 15(5):225-235. https://doi. org/10.1016/0148-9062(78)90955-5

55. Yang SQ, Tian WL, Ranjith PG (2017) Failure mechanical behavior of Australian Strathbogie granite at high temperatures: insights from particle flow modeling. Energies 10:756. https://doi.org/10. 3390/en10060756

56. Zhai J, Zhou M (2000) Finite element analysis of micromechanical failure modes in a heterogeneous ceramic material system. Int J Fract 101(1-2):161-180. https://doi.org/10.1023/A: 1007545105723

57. Zhang XP, Ji PQ, Peng J, Wu SC, Zhang Q (2020) A grain-based model considering pre-existing cracks for modelling mechanical properties of crystalline rock. Comput Geotech 127:103776. https://doi.org/10.1016/j.compgeo.2020.103776

58. Zhu X, Liu W, He X (2017) The investigation of rock indentation simulation based on discrete element method. KSCE J Civ Eng 21(4):1201-1212. https://doi.org/10.1007/s12205-016-0033-4

Publisher's Note Springer Nature remains neutral with regard to jurisdictional claims in published maps and institutional affiliations. 